Harvard Journal of Law \& Technology

Volume 26, Number 1 Fall 2012

\title{
Protecting Open Innovation: The Defensive Patent License as a New Approach to Patent Threats, Transaction Costs, and TaCTICAl Disarmament
}

\author{
Jason Schultz and Jennifer M. Urban*
}

TABLE OF CONTENTS

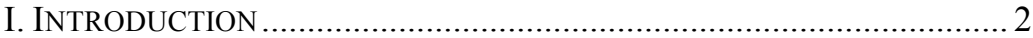

II. OPEN INNOVATION PATENTING: BENEFITS AND BARRIERS ............... 6

A. The Costs and Benefits of Defensive Patenting............................ 6

B. The Cultural and Political Barriers to OIC Patenting ............... 10

C. The Reliability of OIC Patenting Promises ............................... 14

III. A FRAMEWORK FOR EVALUATING OIC PATENT

STRATEGIES 15

A. Drawing Foundational Principles from the OIC

Literature and Practice.

1. OIC Theories, Values, and Practices...

2. Principles Derived from OIC Theory, Values, and

Practices

A. Principle One: Commitment to Freedom ..............................2

i. Freedom to Operate and Freedom to Innovate ............... 21

B. Principle Two: Commitment to Openness ............................. 22

i. Access to Knowledge........................................................... 22

ii. Transparent and Non-Discriminatory Legal

Terms and Enforcement Conditions....

iii. Interoperability and Technology Neutrality

C. Principle Three: Distributed Costs and Benefits

D. Principle Four: Reliability....

* Jason Schultz and Jennifer M. Urban are Assistant Clinical Professors of Law at the UC Berkeley School of Law.

The authors are enormously grateful to the scholars and patent attorneys who have generously offered their thoughts and ideas on this paper and the Defensive Patent License. We have incorporated some of these ideas into this draft; some we are still considering. Of course, not everyone agrees with all we say here, and all errors remain entirely ours. We wish to thank Lila Bailey, Michael Barclay, Keith Bergelt, Dan Burk, Colleen Chien, Kevin Collins, Matt Frost, David Hayes, Brian Kahin, Brewster Kahle, Amy Kapczynski, Ben Lee, Mark Lemley, Alexander Macgillivray, Laura Majerus, Clint Martin, Charles McManis (and his IP Colloquium students), Peter Menell, Michael McGeary, Robert Merges, Florian Mueller, Julie Samuels, Pamela Samuelson, Eric Schulman, Eric Talley, Molly Van Houweling, Mark Webbink, Bart Wise, and Jonathan Zittrain, as well as the participants in the Berkeley Law IP Scholars Seminar, the University of Colorado FOSS Conference, the Santa Clara Law Defense 2.0 Conference, the Open Video Conference, the Stanford CIS lecture series, and the Washington University workshop for their valuable input to this article. We also wish to thank Justin Malone, Bradford Labonte, and Camilla Hrdy for their excellent research assistance. 

i. Longevity .25

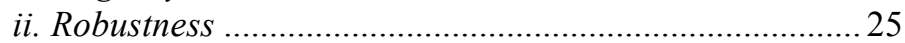
B. Existing OIC Patent Defense Strategies ..................................26

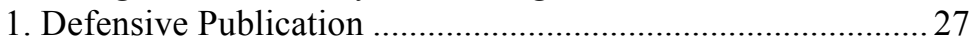

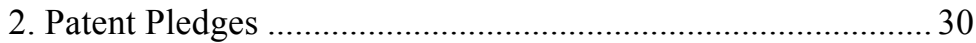
3. Patent "Peace" Provisions ......................................................... 33
4. Patent Protection Groups: The Open Innovation
Network Model ..................................................................... 34
C. Synthesizing a Defensive Patent Strategy for OICs ................... 37

\section{The Defensive PATENT License: A NeW STRATEGy FOR

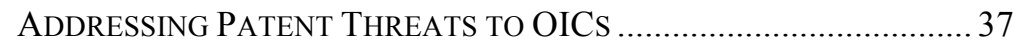

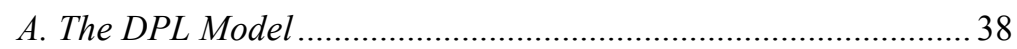 \\ B. Analyzing the DPL under the OIC Patent Defense}

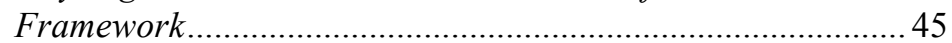
1. Distribution of Costs and Benefits ........................................ 45

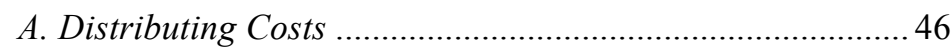

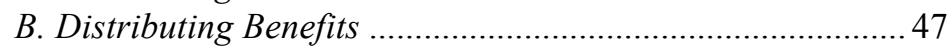
C. Possible Challenges to Generating Network Effects ........... 48 $i$. Balancing Barriers Created by the All-In

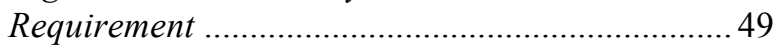
ii. Concerns about Capital Investment ...................................51
2. Respect for Relevant Cultural and Political Values ................. 52

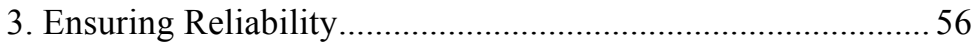

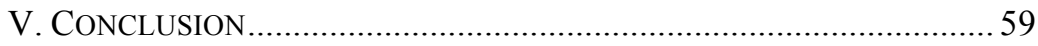

ApPendix One: Model Defensive Patent LiCEnSE .......................... 61

\section{INTRODUCTION}

Historically, Open Innovation Communities (“OICs"), ${ }^{1}$ ranging from those who make free and open source software ("FOSS") projects to various do-it-yourself hardware manufacturing, ${ }^{2} 3 \mathrm{D}$ printing, ${ }^{3}$ synthetic biology projects, ${ }^{4}$ and green technologies, ${ }^{5}$ have struggled to

1. We define OICs as organizations and collections of individuals that value sharing technologies and information as broadly as possible with a substantial commitment to user freedoms. As discussed below, OICs adopt this strategy for a variety of economic and cultural reasons. These companies, academic institutions, nonprofits, and project-based communities generally either grew out of the Free and Open Source Software ("FOSS") movement or for strategic or mission-based reasons adopted FOSS-inspired open innovation approaches.

2. See, e.g., Open SOURCE HARDwARE \& DeSign Alliance, http://www.ohanda.org (last visited Dec. 22, 2012); OPEN HARDWARE SUMMIT, http:// www.openhardwaresummit.org (last visited Dec. 22, 2012).

3. See, e.g., Frequently Asked Questions, MAKERBOT, http://www.makerbot.com/faq (last visited Dec. 22, 2012).

4. See, e.g., About, BIOBRICKS FOUND., http://biobricks.org/about-foundation (last visited Dec. 22, 2012). 
decide what role they should give the patent system in their approaches to innovation, production, and distribution. ${ }^{6}$ Often, their answer has been "none at all."

We believe this is for three reasons. First, patents are expensive to acquire and enforce. In order to acquire a significant patent portfolio, a firm must dedicate substantial labor and fiscal resources, first to prosecuting or purchasing patents and then to enforcement, negotiation, and licensing efforts in response to affirmative threats. ${ }^{7}$ These economics tend to favor large proprietary firms and consortia that are able to concentrate costs and benefits. ${ }^{8}$ Such economics make patenting far more difficult in OICs, which are generally structured to distribute costs and benefits through decentralized decision-making and resource allocation. ${ }^{9}$

Second, patents are often considered philosophically, culturally, and politically anathema to OIC members, especially software programmers. Many innovators in these fields see patents as anticompetitive and associate their use with anti-innovation "bullying" tactics by both dominant industry players and so-called "patent trolls." $" 10$ Within the software and information industries, there are also strong objections to patents based on the belief that they tend to be overbroad, weak, and indeterminate in scope. ${ }^{11}$ There are also objec-

5. See Andrew Boynton, Eco-Patent Commons: A Donation Approach Encouraging Innovation Within the Patent System, 35 WM. \& MARY ENVTL. L. \& POL'Y REV. 659, 674 (2011).

6. See Sara Boettiger \& Dan L. Burk, Open Source Patenting, 1 J. INT'L Biotechnology L. 221, 221 (2004); Symposium on Bioinformatics and Intellectual Property Law, Open Source Genomics, 8 B.U. J. ScI. \& TECH. L. 254, 254-62 (2002). See generally JANET HOPE, BIOBAZAAR: THE OPEN SOURCE REVOlution AND BIOTECHNOLOGY (2008) (discussing the use in biotechnology of open source principles to counteract innovation lockdown caused by exclusive rights); Andrew W. Torrance, Open Source Human Evolution, 30 WASH. U. J.L. \& POL'Y 93 (2009) (discussing the use in genetic engineering of the patent system and an alternative open source approach).

7. See, e.g., Shira Ovide, Google-Motorola: It's All About the Patents, WALL St. J. DEAL J. (Aug. 15, 2011, 10:03 AM), http://blogs.wsj.com/deals/2011/08/15/google-motorola-itsall-about-the-patents.

8. See, e.g., id.

9. See Yochai Benkler, The Wealth of Networks 59-60 (2006); Paul Vixie, Software Engineering, in OPEN SOURCES 91, 96-99 (Chris DiBona et al. eds., 1999).

10. See infra Part II.B.

11. In this objection, software innovators are joined by various members of the academy. See, e.g., JAmes Bessen \& Michael J. Meurer, Patent Failure: How Judges, BUREAUCRATS, AND LAWYERS PUT INNOVATORS AT RISK 187-200 (2008); ADAM B. JAFFE \& JOSH LERNER, INNOVATION AND ITS DISCONTENTS: HOW OUR BROKEN PATENT SYSTEM IS ENDANGERING INNOVATION AND PROGRESS, AND WHAT TO DO ABOUT IT 56-78 (2004). The legal academy is split, however, on the questions of how serious this issue is and how to address it. See, e.g., John R. Allison \& Ronald J. Mann, The Disputed Quality of Software Patents, 85 WASH. U. L. ReV. 297, 302-03 (2007); Robert P. Merges, As Many as Six Impossible Patents Before Breakfast: Property Rights for Business Concepts and Patent System Reform, 14 BERKELEY TeCH. L.J. 577, 581-84 (1999); Pamela Samuelson \& Jason Schultz, "Clues" for Determining Whether Business and Service Innovations Are Unpatentable Abstract Ideas, 15 LEWIS \& CLARK L. REV. 109, 127 (2010). 
tions to patents that cover software, business methods, and the like as ethically inappropriate or scientifically questionable attempts to own and control mathematical formulas and other laws of nature. ${ }^{12}$

Third, even when patents appear to be acquired for "defensive" or other altruistic purposes, there has been no guarantee against someone "weaponizing" them in the future for use in an offensive attack. ${ }^{13} \mathrm{~A}$ range of companies, especially those in the software, hardware, and semiconductor fields, have described their patent portfolios as "defensive," and in some cases have made promises to this effect; however, these companies have not always made legally binding commitments to keep those promises. ${ }^{14}$ Some of these companies have then allowed "defensive" patents to be used or sold for offensive purposes or have been forced by investors or through bankruptcy proceedings to sell them to entities that might use them for offensive purposes. ${ }^{15}$ Even socalled "patent pledges" not to assert patents offensively have raised significant questions as to their enforceability and scope. ${ }^{16}$ This has led to further trepidation about patenting for OICs, especially with the rise of relatively new patent portfolio owners whose intentions may not align with the previous patent portfolio owners. ${ }^{17}$

12. See Ben Klemens, Math You Can't Use: Patents, Copyright, And Software 44-72 (2005), available at http://www.e-reading.org.ua/bookreader.php/133502/Math You_Can\%60t_Use\%3A_Patents,_Copyright,_and_Software.pdf; Richard Stallman, Patent Absurdity, GUARDIAN (June 22, 2005), http://www.guardian.co.uk/technology/2005/jun/ 23/onlinesupplement.insideit.

13. See, e.g., Andy Baio, A Patent Lie: How Yahoo Weaponized My Work, WIRED (Mar. 13, 2012), http://www.wired.com/business/2012/03/opinion-baio-yahoo-patent-lie.

14. Examples include companies from Microsoft to Red Hat (a FOSS firm). See Dennis Crouch \& Jason Rantanen, Defensive Patenting, PATENTLY-O (May 4, 2004, 10:22 AM), http://www.patentlyo.com/patent/2004/05/defensive_paten.html; Dj Walker-Morgan, Red Hat "Defensive" Patent Has Chilling Effect, H OPEN (Mar. 16, 2009, 1:37 PM), http://www.h-online.com/open/news/item/Red-Hat-defensive-patent-has-chilling-effect740575.html. Another company, RPX, buys up or licenses patents and then licenses them out to companies that sign up for a substantial fee. RPX describes itself as a "defensive patent aggregator," though it has been criticized as little more than a "troll" that charges companies for protection against suit. See RPX Fattens up on Saxon Innovations Patent Portfolio, PRIOR ART (Mar. 2, 2010, 2:25 $\quad$ PM), http://thepriorart.typepad.com/the_prior_art/2010/03/rpx-buys-saxon-innovationspatents.html; RPX Introduces First Defensive Patent Aggregation Service; First Members Include Technology Leaders, Business WIRE (Nov. 25, 2008), http://www.bloomberg.com/apps/news?pid=newsarchive\&sid=aKFVwBx0C1v4; Erick Schonfeld, Is RPX's “Defensive Patent Aggregation” Simply Patent Extortion by Another Name?, TECHCRUNCH (Nov. 24, 2008), http://techcrunch.com/2008/11/24/is-rpxsdefensive-patent-aggregation-simply-patent-extortion-by-another-name.

15. See, e.g., Alorie Gilbert, Commerce One Patent Sale Has Google Worried, ZDNET UK (Nov. 25, 2004) [hereinafter Gilbert, Commerce One], available at Factiva, Doc. No. ZDNTUK0020051020e0bp0001h (describing the Commerce One bankruptcy proceeding, which involved thirty-nine patents on broad aspects of Web services).

16. See, e.g., Florian Mueller, IBM Breaks the Taboo and Betrays Its Promise to the FOSS Community, FOSS PATENTS (Apr. 6, 2010, 8:11 AM), http://fosspatents.blogspot.com/2010/04/ibm-breaks-taboo-and-betrays-its.html.

17. See, e.g., Steve Lohr, Turning Patents into 'Invention Capital,' N.Y. TIMES (Feb. 17, 2010), http://www.nytimes.com/2010/02/18/technology/18patent.html; Michael Rose, Nor- 
In this Article, we seek to question and reinvigorate the debate over if, when, how, and why OICs might use patents. We start by analyzing the three main reasons why OICs opt out of the patent system. We then look at how various OICs have approached strategic concerns about intellectual property and derive a framework for evaluating OIC patent defense strategies.

We then make a case for why OICs should - and indeed must opt back into the patent system if they wish to protect themselves from the growing threats that patents pose, including threats from the increasingly complex "thicket" of patents on software, standards, and ecosystems that have become the battlegrounds for technologies such as smartphones, online media, and social media. ${ }^{18}$ To be clear, we are certainly sympathetic to OICs' concerns about patent subject matter and scope; effectively addressing the breadth of patents could address many concerns about patent threats. But the Supreme Court's decisions in Bilski v. Kappos ${ }^{19}$ and Mayo v. Prometheus ${ }^{20}$ indicate that software and some other abstract patents are here to stay for the foreseeable future. Similarly, the America Invents $\mathrm{Act}^{21}$ shows that Congress is also unlikely to fundamentally reform patentable subject matter or patent scope anytime soon. Given this, making the system as it exists safer for innovation may be the most practical approach for now.

We support our argument with a proposal for a new OIC patent license - the Defensive Patent License ("DPL"). The DPL is a form of patent license that serves as the connection point for a distributed defensive cross-license network. Built on legal and normative approaches similar to the GNU General Public License ${ }^{22}$ and Creative

tel Patent Auction Goes to Apple/Microsoft/RIM Consortium, UnOfFiCial APPLE WeBloG (July 1, 2011, 6:45 AM), http://www.tuaw.com/2011/07/01/nortel-patent-auction-goes-toapple-microsoft-rim-consortium; When Patents Attack!, THIS AMERICAN LifE (July 22, 2011), http://www.thisamericanlife.org/radio-archives/episode/441/when-patents-attack.

18. See, e.g., Ingrid Lunden, Spotify Gets Hit with a Patent Suit from Nonend, a Dutch Peer-to-Peer IP Holder, TECHCRUNCH (Aug. 15, 2012), http://techcrunch.com/ 2012/08/15/spotify-gets-hit-with-a-patent-suit-from-nonend-a-dutch-peer-to-peer-ip-holder; Baio, supra note 13; Press Release, Public Knowledge, Public Knowledge Warns of Threats to 3D Printing (Nov. 10, 2010), http://www.publicknowledge.org/ public-knowledge-warns-threats-3d-printing; Dan Rowinski, Chart of the Day: Who Is Suing Whom in the Mobile Patent Wars?, READWRITEMoBiLE (Aug. 18, 2011), http://www.readwriteweb.com/mobile/2011/08/chart-of-the-day-who-is-suing.php; Erick Schonfeld, Brightcove Streaming 700 Million Videos a Month; Granted Broad Patent for Online Video, TECHCRUNCH (May 2, 2011), http://techcrunch.com/2011/05/02/brightcove700-million-videos-patent; Todd Spangler, Verizon To Pay TiVo \$250M To Settle Patent Lawsuit, MultichanNel News (Sept. 24, 2012, 7:29 AM), http://www.multichannel.com/ news-article/verizon-pay-tivo-250m-settle-patent-lawsuit/139417.

19. Bilski v. Kappos, 130 S. Ct. 3218 (2010).

20. Mayo Collaborative Servs. v. Prometheus Labs., Inc., 132 S. Ct. 1289 (2012).

21. Obama Signs Patent Reform Bill, CNN.COM (Sept. 16, 2011, 12:02 PM), http://www.cnn.com/2011/POLITICS/09/16/obama.patent.reform.

22. See GNU General Public License v3.0, GNU OPERATING SYS. (June 29, 2007), http://www.gnu.org/copyleft/gpl.html. 
Commons licensing, ${ }^{23}$ the DPL directly addresses the three reasons for OIC opt-out and provides several incentives for opting in, including (1) increasing access and interoperability between OIC technologies, (2) improving the prior art, (3) imposing legally binding restrictions that require DPL patents to remain "defensive," and (4) preventing patent trolls, "bullies," DPL patents against those who use the license. ${ }^{25} \mathrm{We}$ end with a comparison of the DPL to other OIC patent strategies.

\section{OPEN INNOVATION PATENTING: BENEFITS AND BARRIERS}

To better understand why OICs opt out of the current patent system, we first examine one of the primary strategic reasons that proprietary innovation communities patent: defensive patenting. Below we examine the costs and benefits of this strategy and consider additional reasons why OIC firms have largely failed to adopt a similar approach.

\section{A. The Costs and Benefits of Defensive Patenting}

In its most basic form, defensive patenting is the practice of seeking patents in order to deter offensive lawsuits rather than to gain more traditional patent benefits, such as seeking licensing revenue, facilitating joint research and development, or excluding competitors. ${ }^{26}$ To engage in defensive patenting, competitors within an industry each build significant patent portfolios and then threaten to use those portfolios in response to offensive patent threats. ${ }^{27}$ The greater the size and scope of a given firm's portfolio, the more dangerous and costly it is to litigate against, thus serving as an ex ante deterrent. ${ }^{28}$ These costs include not only those of litigating the patents, but also

23. See About, CREATIVE COMMONS, http://creativecommons.org/about (last visited Dec. 22, 2012).

24. Colleen V. Chien, Of Trolls, Davids, Goliaths, and Kings: Narratives and Evidence in the Litigation of High-Tech Patents, 87 N.C. L. REV. 1571, 1588 (2009) (introducing the term patent "bullies").

25. We recognize, of course, that our proposal may be the second-best solution and that direct reform to the patent system through the courts, Congress, or the U.S. Patent and Trademark Office might be preferable. However, unless and until such reform occurs, we believe private ordering solutions such as the DPL can continue to improve the patent situation for OICs and provide concrete social welfare benefits.

26. See Chien, supra note 24 , at 1582.

27. See, e.g., Jennifer Jones, Adobe, Macromedia Settle Patent Suits, ZDNET (July 30, 2012, 12:00 PM), http:/www.zdnet.com/news/adobe-macromedia-settle-patent-suits/ 124272 (detailing series of patent suits between competitors Adobe and Macromedia).

28. See The Tuesday Podcast: The Patent War, NPR (Aug. 2, 2011), http://www.npr.org/ blogs/money/2011/08/05/138934689/the-tuesday-podcast-the-patent-war (referring to this behavior as similar to the "mutually assured destruction" approach used by superpowers during the Cold War). 
the high information costs associated with evaluating what are often dozens if not hundreds of opposing claims on both infringement and invalidity grounds. ${ }^{29}$ In well-resourced and patent-heavy industries, such as semiconductor manufacturing, ${ }^{30}$ these costs and the potential downsides of litigation ${ }^{31}$ can lead to cross-licensing détentes, with significant players either preemptively agreeing to avoid litigation or leveraging defensive patents to resolve disputes after litigation has commenced. ${ }^{32}$ In light of these benefits, the practice of building a defensive patent portfolio is a common intellectual property strategy of many proprietary innovation firms.

It is worth noting, however, that defensive patenting does not work against all potential patent plaintiffs. While it has generally been effective against competitors who share the same high costs of litigation, such as so-called patent "bullies" who might threaten smaller competitors or new entrants to a field, ${ }^{33}$ it has generally failed to deter (and in some ways may have even inspired) so-called "patent trolls," who often acquire otherwise inactive patents and file or threaten lawsuits for the sole purpose of generating licensing income. ${ }^{34}$ Because trolls cannot be countersued - they do not make, use, import, sell, or

29. See Gene Quinn, The Cost of Obtaining a Patent in the US, IPWATCHDOG (Jan. 28, 2011, 1:14 PM), http://ipwatchdog.com/2011/01/28/the-cost-of-obtaining-patent/id=14668; see also Am. Intellectual Prop. LAW Ass'N, LAW Practice MGMT. Comm., 2011 REPORT OF THE ECONOMIC SURVEY 35 (2011) (noting the high cost of patent litigation).

30. See Carl Shapiro, Navigating the Patent Thicket: Cross Licenses, Patent Pools, and Standard Setting, in 1 InNOVATION POLICY AND THE ECONOMY 119, 119-121 (Adam B. Jaffe et al. eds., 2001), available at http:/faculty.haas.berkeley.edu/shapiro/thicket.pdf; Alberto Galasso, Broad Cross-License Agreements and Persuasive Patent Litigation: Theory and Evidence from the Semiconductor Industry 3-4 (London Sch. Econ. \& Pol. Sci. Suntory \& Toyota Int'l Centres for Econ. \& Related Disciplines, Research Paper No. EI45, 2007), available at http://papers.ssrn.com/soL3/papers.cfm?abstract_id=1158322.

31. Recent lawsuits provide examples of how expensive losing patent litigation can be. See Rob Kelley, BlackBerry Maker, NTP Ink \$612 Million Settlement, CNNMONEY.COM (Mar. 3, 2006, 7:29 PM), http://money.cnn.com/2006/03/03/technology/rimm_ntp (announcing that RIM settled patent dispute for $\$ 612$ million); see also i4i Ltd. P'ship v. Microsoft Corp., 598 F.3d 831, 852-64 (Fed. Cir. 2010) (affirming damages award in excess of $\$ 200$ million plus permanent injunction), aff'd, 131 S. Ct. 2238 (2011).

32. Colleen V. Chien, From Arms Race to Marketplace: The Complex Patent Ecosystem and Its Implications for the Patent System, 62 HASTINGS L.J. 297, 308 (2010). For examples, see Fairchild Semiconductor and Infineon Reach Patent Settlement, Cross-License, EDACAFÉ (Dec. 28, 2009), http://www10.edacafe.com/nbc/articles/view article.php?articleid $=774510$, and Hologic Settles J\&J Subsidiary Patent Dispute, MASS HigH TECH (Feb. 22, 2010), http://www.masshightech.com/stories/2010/02/22/daily1Hologic-settles-JJ-subsidiary-patent-dispute.html.

33. See Ted M. Sichelman, The Vonage Trilogy: A Case Study in "Patent Bullying," (San Diego Legal Studies, Paper No. 11-057, 2011), available at http://ssrn.com/ abstract $=1856703$.

34. While there is some debate over the definition of a "patent troll," see Michael Risch, Patent Troll Myths, 42 SETON HALl L. REV. 457, 462-66 (2012), we use the term generally to mean patent litigation plaintiffs that have neither practiced, researched, nor developed the technology claimed in the patent-in-suit in any significant or substantial way. While others prefer the term "non-practicing entities," $i d$., we find that term too limited in some contexts, such as academic research institutions. 
offer for sale anything that could be infringing, inoculating them against suit - a defensive portfolio has little effect against them. However, the patents in a defensive portfolio, if later acquired by a troll, could become weapons to wield against other defendants.

The defensive patenting strategy works for traditional proprietary innovation firms, in part, because the most significant costs - patent prosecution, portfolio management, litigation, and licensing negotiation - can be concentrated relatively easily within a firm's legal department. Microsoft can justify the cost of filing for 3000 patents per year because the benefit of having 3000 potential counterstrikes against a future patent threat presumably outweighs those costs. ${ }^{35} \mathrm{Mi}-$ crosoft can also internalize both the costs and benefits. For example, Microsoft can afford the patent application and maintenance fees, the cost of tracking and maintaining its portfolio, the cost of patent prosecution and licensing advice, and it can hire in-house patent counsel to coordinate patent strategy efficiently and under the protections of the attorney-client privilege, all of which suggest economies-of-scale efficiencies. ${ }^{36}$ The benefits are also clearly definable and to some degree measurable - a reduction in the costs imposed on the firm by patent litigation.

OIC firms, however, have much more difficulty achieving this balance. First, individual OICs often lack the legal and fiscal resources to build and enforce large patent portfolios, to absorb the information costs of understanding oppositional portfolios, or to incur the transaction costs of forming cross-license agreements. ${ }^{37}$ While some larger OIC players - Google, Novell, IBM, and Red Hat in particular $^{38}$ - have both in-house and outside patent counsel to shoulder some of this burden, many of their collaborators within the Linux operating system, open web, and Android mobile OS ecosystems are either volunteer projects, nonprofit foundations, or startups, and cannot absorb these costs. Second, many OICs, especially FOSS projects, are decentralized or organized outside of formal corporate structures, and thus incur significant coordination costs whenever there are efforts to collaborate across projects or firms. This is particularly true when it comes to legal strategy, as such projects tend to

35. Press Release, Microsoft, Microsoft Appoints Marshall Phelps Corporate Vice President and Deputy General Counsel for Intellectual Property (June 5, 2003), http://www.microsoft.com/presspass/press/2003/jun03/06-05dgcpr.mspx.

36. Id.

37. See Rebecca S. Eisenberg, Patent Costs and Unlicensed Use of Patented Inventions, 78 U. CHI. L. REV. 53, 55 (2011) ("Information costs and transaction costs may dwarf potential gains to users from identifying and clearing rights or to owners from identifying infringers and asserting rights against them." (citation omitted)).

38. See Jon Brodkin, Linux Patent Protection Network Gets Boost from Facebook, HP, NETWORK WORLD (Apr. 20, 2011, 12:04 AM), http:/www.networkworld.com/news/ 2011/042011-linux-patent-protection.html (discussing the membership and patent portfolio of the Open Invention Network). 
have few, if any, lawyers on staff. This is one reason why OICs rely on distributed and decentralized means of production to create technologies. By employing distributed production techniques that operate via purposeful openness and sharing, they are able to distribute the costs and benefits throughout the community and take advantage of the network effects of their production processes.

In the legal arena, OICs have also sought to decentralize costs and to use network effects to maximize benefits by employing scalable and standardized "off-the-shelf" intellectual property licenses that do not require downstream lawyer involvement. This is in part because decentralized production strategies present some significant challenges. For example, obtaining legal advice under the attorney-client privilege is far more difficult when the engineers who will implement the advice are volunteers who may be distributed over dozens of physical locations worldwide and who mainly communicate through public email lists or centralized code repositories. ${ }^{39}$ This is one reason why the use of standardized licenses such as the GPL and Creative Commons have been so popular among OICs. Once developed, they provide scalable legal tools to promote decentralized participation and administration of creative production without requiring significant additional legal or fiscal resources. ${ }^{40}$ However, these strategies have some significant limits when case-by-case legal questions or transactions arise.

Traditional defensive patenting presents such a situation, as it does not scale as easily as copyright licensing. Unlike obtaining a copyright, obtaining a patent is not automatic, and involves significant prosecution and administration costs. ${ }^{41}$ On top of this, the costs of patent portfolio management, analysis of oppositional claims and likely threats, licensing and negotiation, and litigation are all much more significant for patents than for copyrights. ${ }^{42}$

39. See, e.g., phpWebSite Content Management System Forums, SoURCEFORGE, http://sourceforge.net/projects/phpwebsite/forums (last visited Dec. 22, 2012) (providing examples of the types of public or semi-public legal conversations engineers working on open development projects may have); Mailing List Archives: Legal-discuss@apache.org, LEGAL-DISCUSS@APACHE.ORG ARCHIVES, http://mail-archives.apache.org/mod_mbox/ www-legal-discuss (last updated Dec. 22, 2012) (same).

40. See Get Creative, CREATIVE COMMONS, http://mirrors.creativecommons.org/ getcreative (last visited Dec. 22, 2012) (explaining the use of Creative Commons licenses).

41. Montgomery v. Noga, 168 F.3d 1282, 1288 (11th Cir. 1999).

42. The very nature of patent infringement differs from copyright infringement in ways that make decentralized legal defense of patent threats much more challenging. With copyright, one cannot be liable for infringement without either evidence of literal copying or access to the plaintiff's work coupled with evidence of substantial similarity between the two works. E.g., Three Boys Music Corp. v. Bolton, 212 F.3d 477, 481 (9th Cir. 2000). This means that OICs that develop original computer code are quite unlikely to be accused of copyright infringement. By contrast, one can infringe patents unknowingly, even when writing original code. Global-Tech Appliances, Inc. v. SEB S.A., 131 S. Ct. 2060, 2065 n.2 (2011) ("[A] direct infringer's knowledge or intent is irrelevant."). This makes it much more difficult for OICs to predict and avoid patent infringement claims. As we discuss below, the 
Thus, in order for OICs to take advantage of a defensive patent strategy, that strategy would have to address these costs and concerns and ensure that enough benefits accrue to the OIC to outweigh them. In particular, given the general distributed structure for OIC costs and benefits, a successful defensive patent strategy must either take advantage of the same distributive economics or somehow compensate for the lack of traditional firm concentrations in these areas.

\section{B. The Cultural and Political Barriers to OIC Patenting}

Cost-benefit challenges are the most straightforward reason why OICs might have shown limited interest in opting in to the patent system, but there are additional significant reasons, including the strong cultural and political preferences against patents held by many OIC participants. OICs have historically disfavored patents, especially on software and information goods. ${ }^{43}$ As described further in Part II, for both philosophical and practical reasons, many in OIC communities reject the exclusive, proprietary models of innovation and production that patents have traditionally undergirded. It is common for OIC advocates to consider patents anti-competitive, anti-innovative, and antithetical to rapid development and to the spirit of openness and freedom. ${ }^{44}$ While this is certainly true of a strong contingent in the FOSS community, it is also true within many parts of the proprietary software community. "When Patents Attack," a National Public Ra-

traditional open licenses are only able to curb the behavior of other OIC parties and therefore have not been able to provide sufficient protection against patent claims by non-OIC parties.

43. See supra note 6.

44. See Richard Stallman, Beware: Europe's 'Unitary Patent' Could Mean Unlimited Software Patents, GuARDiAn (Aug. 22, 2011, 7:43 AM), http://www.guardian.co.uk/ technology/2011/aug/22/european-unitary-patent-software-warning ("Software patents are dangerous to software developers because they impose monopolies on software ideas. It is not feasible or safe to develop non-trivial software if you must thread a maze of patents."); Jeff Bezos, An Open Letter from Jeff Bezos on the Subject of Patents, O'REILLY (Mar. 9, 2000), http://oreilly.com/news/amazon_patents.html; Ingrid Marson, Linus Torvalds Speaks Out Against EU Patent Law, ZDNET (Nov. 23, 2004, 12:35 PM), http://www.zdnet.com/ linus-torvalds-speaks-out-against-eu-patent-law-3039174746; Roy Schestowitz, Tim O'Reilly (US): "We Need Some Serious Reform on Software Patents.", TECHRIGHTS (June 3, 2011, 1:33 AM), http://techrights.org/2011/06/03/tim-oreilly-on-swpats.

45. See When Patents Attack!, supra note 17; see also Timothy B. Lee, A Patent Lie, N.Y. TIMES, June 9, 2007, at A15, available at http://www.nytimes.com/2007/06/09/opinion/09lee.html; Mark Cuban, My Suggestion on Patent Law, HufF Post Bus. (Aug. 8, 2011, 2:29 PM), http://www.huffingtonpost.com/mark-cuban/my-suggestion-on-patent-1_b_921198.html;

Mike Masnick, By Definition, a Defensive Patent Is a Bad Patent, TeCHDIRT (July 29, 2011, 6:36 PM), http://www.techdirt.com/articles/20110729/03340615311/definition-defensivepatent-is-bad-patent.shtml; Mike Masnick, 'What Idiot Wrote The Patent That Might Invalidate Software Patents? Oh, Wait, That Was Me,' TECHDIRT (Aug. 23, 2011, 9:46 AM), http://www.techdirt.com/articles/20110822/13094215621/what-idiot-wrote-patent-thatmight-invalidate-software-patents-oh-wait-that-was-me.shtml. 
dio ("NPR") report, provides an example of the strong perception that patents are a negative force in the software and information industries:

[W]e talked to a half dozen different software engineers. All of them hated the patent system, and half of them had patents in their names that they felt shouldn't have been granted. In polls, as many as 80 percent of software engineers say the patent system actually hinders innovation. It doesn't encourage them to come up with new ideas and create new products. It actually gets in their way.

Many patents are so broad, engineers say, that everyone's guilty of infringement. This causes huge problems for almost anyone trying to start or grow a business on the Internet. ${ }^{46}$

As suggested by the NPR story, longstanding questions about the status of software and other informational innovations as patentable subject matter, and uncertainty concerning the boundaries of patent protection in these areas, have likely contributed to these negative perceptions of patents in OICs. In general, laws of nature, discovered facts, and abstractions (such as mathematical equations) are unpatentable, owing both to the constitutional origins of patenting and to concerns over the impact that patents on broad principles and ideas could have on downstream innovation. ${ }^{47}$ How software fits into patentable subject matter has been contested since its entry into the modern consumer marketplace, and new products and services periodically reinvigorate the longstanding debate among the federal judiciary, intellectual property policymakers, and academic commentators about the extent information products and services should be patentable. ${ }^{48}$

\footnotetext{
46. When Patents Attack, NPR (July 26, 2011, 3:00 PM), http://www.npr.org/blogs/money/2011/07/26/138576167/when-patents-attack (promoting When Patents Attack!, supra note 17).

47. See Mayo Collaborative Servs. v. Prometheus Labs., Inc., 132 S. Ct. 1289, 1293-94 (2012); Lab. Corp. of Am. Holdings v. Metabolite Labs., Inc., 548 U.S. 124, 126-27 (2006) (Breyer, J., dissenting). See generally Samuelson \& Schultz, supra note 11 (discussing patentability clues derived from the Constitution and effects on downstream innovation).

48. We will not revisit the entire longstanding and wide-ranging debate here, but offer a few viewpoints. For commentary critical of software patents on subject matter grounds, see KLEMENS, supra note 12, at 44; Brief of Professors Peter S. Menell and Michael J. Meurer as Amici Curiae Supporting Respondent, Bilski v. Kappos, 130 S. Ct. 3218 (2010) (No. 08964); Pamela Samuelson, Benson Revisited: The Case Against Patent Protection for Algorithms and Other Computer Program-Related Inventions, 39 EMORY L.J. 1025 (1990). Beyond academic commentators, OIC and other industry commentators share their views in Luca Lucarini's film, PATENT ABSURDITY (Jamie King May 4, 2010), available at http://patentabsurdity.com. Some concerns about abstract patents focus on the patenting process rather than directly on the question of patentable subject matter. For example, Rob-
} 
Typically, OIC firms have come down strongly on the side of limiting patentable subject matter in this area, in part because they have not traditionally relied upon patents as incentives for their own production, and in part because they fear software patents being wielded as a mechanism for reducing their ability to innovate freely.

OIC cultural objections to software and other abstract patents developed in parallel with case law that established software as patentable subject matter. In a series of highly contested rulings through the 1970s and 1980s, the Supreme Court struggled with the subject matter issue, ${ }^{49}$ eventually deciding 5-4 in the 1981 case Diamond $v$. Diehr that software that "transform[ed] or reduc[ed] an article to a different state or thing" could be patentable. ${ }^{50}$ For over a decade after Diehr, the patent-specialist Federal Circuit Court of Appeals engaged in its own internal battle over the limits of software patentability. It eventually decided en banc in the 1994 case In re Alappat that a generalpurpose computer running novel and nonobvious software was a patentable "new machine" under the statutory language of the Patent Act. ${ }^{51}$ After Alappat, the Federal Circuit allowed patents on increasingly more abstract inventions, culminating in State Street Bank \& Trust Co. v. Signature Financial Group, a 1998 case in which the court held that a hub-and-spoke method for mutual fund investing was patentable. ${ }^{52}$ This resulted in the U.S. Patent and Trademark Office ("USPTO") granting a set of broad, criticized patents - for example, a patent to Amazon on one-click online shopping ${ }^{53}$ - resulting in a backlash in the information industries ${ }^{54}$ and at least one Supreme Court dissent that appeared to question the Federal Circuit's approach. ${ }^{55}$

In 2008, the Federal Circuit stepped back somewhat from State Street, holding en banc in In re Bilski that a patent on a method of hedging financial risk in commodity trading that claimed neither a

ert Merges, while remaining agnostic to software and other abstract patents on subject matter grounds, argues for reforms in the patenting process in order to weed out overbroad or otherwise poor-quality patents. See Merges, supra note 11, at 598. And others argue strongly for the patentability of software. See Ronald J. Mann, Do Patents Facilitate Financing in the Software Industry?, 83 TEX. L. REV. 961, 963-64 (2005).

49. See Diamond v. Diehr, 450 U.S. 175 (1981); Parker v. Flook, 437 U.S. 584 (1978); Gottschalk v. Benson, 409 U.S. 63 (1972).

50. See Diehr, 450 U.S. at 192.

51. See 33 F.3d 1526, 1545 (Fed. Cir. 1994).

52. 149 F.3d 1368, 1373, 1376 (Fed. Cir. 1998).

53. U.S. Patent No. 5,960,411 (filed Sept. 12, 1997). This patent was the subject of intense litigation, and for several years, a preliminary injunction prevented Barnes \& Noble from using a one-click option. See Amazon.com v. Barnesandnoble.com, 239 F.3d 1343, 1346-47 (Fed. Cir. 2001).

54. David Orozco, Administrative Patent Levers, 117 PENN. ST. L. REV. 1, 22 n.119 (2012) (discussing Free Software Foundation boycott in response to Amazon's assertion of the one-click patent).

55. Lab. Corp. of Am. Holdings v. Metabolite Labs., Inc., 548 U.S. 124, 136 (2006) (Breyer, J., dissenting). 
"new machine" nor a transformation of matter, was a bridge too far. ${ }^{56}$ This decision fueled hope in OICs that patents on software or other abstract information technologies and services might finally be disallowed, or at least narrowly granted. ${ }^{57}$ On appeal, however, the Supreme Court shifted away from this approach and found the Bilski patent invalid under a different rationale: that it was too abstract, and thus non-patentable subject matter. ${ }^{58}$ This left the patentability of software in much less doubt. Therefore, while skepticism in OICs about the appropriateness of software and information patents remains, ${ }^{59}$ they nonetheless must face the threat presented by such patents.

There are also strong objections within OICs to software and information patents' perceived lack of quality and over-reaching breadth. In particular, many OIC advocates have expressed concern that the USPTO issues patents in this sector on incremental improvements that should be considered obvious and grants overbroad claims that allow patentees to threaten entire industries. ${ }^{60}$ This perception that software patents are illegitimate as legal instruments continues today, erupting every few weeks or months when the next objectionable patent issues from the USPTO. ${ }^{61}$

Moreover, the rise of patent trolls has further increased hostility to the idea of patents as beneficial legal tools. ${ }^{62}$ As stories of patent threats against information innovators continue to be reported in the press - especially stories of threats based on patents of perceived lower quality - the attitude toward software patents has continued to sour among developers who already believed that companies should compete on other grounds, such as branding, customer support, quality, and first-mover advantages. ${ }^{63}$ Thus, in order for an OIC patenting

56. See 545 F.3d 943, 963, 975 (Fed. Cir. 2008) (en banc), aff'd, Bilski v. Kappos, $130 \mathrm{~S}$. Ct. 3218 (2010).

57. See William F. Lee et al., Federal Circuit Decision in In re Bilski Has Far-Reaching Implications, WILMERHALE (Oct. 30, 2008), http://www.wilmerhale.com/publications/ whPubsDetail.aspx?publication $=8531$.

58. Bilski, 130 S. Ct. at 3231.

59. See, e.g., Eben Moglen on Bilski, Software Patents, and Big Pharma, PRIOR ART (Aug. 5, 2010), http://thepriorart.typepad.com/the_prior_art/2010/08/eben-moglen-onbilski-software-patents-and-big-pharma.html.

60. See BESSEN \& MEURER, supra note 11, at 18-19, 163.

61. See, e.g., U.S. Patent No. 7,699,123 (filed Aug. 11, 2006) (Facebook's method of providing a news feed of a user's friends' activities); Caroline McCarthy, Facebook's Newsfeed Patent Could Mean Lawsuits, CNN (Feb. 26, 2010), http://articles.cnn.com/2010-0226/tech/facebook.patent_1_facebook-social-media-feed?_s=PM:TECH.

62. See Risch, supra note 34, at 459; James Bessen et al., The Private and Social Costs of Patent Trolls 2 (Bos. Univ. Sch. of Law, Working Paper No. 11-45, 2011), available at http://www.bu.edu/law/faculty/scholarship/workingpapers/Bessen-Ford-Meurer-troll.html; see also eBay Inc. v. MercExchange, L.L.C., 547 U.S. 388, 396-97 (2006) (Kennedy, J., concurring).

63. See, e.g., Jonathan M. Barnett, Private Protection of Patentable Goods, 25 CARDOZO L. REV. 1251, 1251-52 (2004); Stuart J.H. Graham et al., High Technology Entrepreneurs 
strategy to be effective, it would have to address these concerns as well.

\section{The Reliability of OIC Patenting Promises}

Beyond cost concerns and cultural objections, OIC firms are also concerned about the reliability of any promise made by patent holders to use patents for altruistic purposes, such as defensive use only. Patents used only for defensive purposes - in other words, patents that should not pose any threat to OIC firms that do not assert patents themselves - are in theory far less objectionable to the OIC community. Still, concerns remain within OICs that patents allegedly - or initially — prosecuted for defensive purposes will eventually be used offensively. The original patent holder might have a change of heart or business strategy; even if this does not happen, some later successor may choose not to honor a predecessor's pledge. ${ }^{64}$

Where a patent is acquired through a hostile takeover or a bankruptcy proceeding, the original pledge may be particularly vulnerable. For example, as part of the bankruptcy proceeding for web services firm Commerce One, thirty-nine patents that covered basic web protocols went on the auction block, causing concern in Silicon Valley about who would acquire them. ${ }^{65}$ The patents were sufficiently broad to generate fears that a patent troll or a firm with anti-competitive intentions would prevail in the auction and wreak havoc on various aspects of e-commerce. ${ }^{66}$

In addition to entering bankruptcy, firms regularly sell assets including patents - merge with other entities, or are acquired. ${ }^{67}$ Since its inception over a decade ago, Intellectual Ventures, a firm focused on generating revenues from patent licensing rather than making and selling products, has purchased over 30,000 existing patents. ${ }^{68}$ Nortel Networks recently auctioned off over 6000 patents on its way to shut-

and the Patent System: Results of the 2008 Berkeley Patent Survey, 24 BERKELEY TECH. L.J. 1255, 1255, 1277 (2009); Samuelson \& Schultz, supra note 11, at 109; Cuban, supra note 45.

64. See, e.g., Gilbert, Commerce One, supra note 15.

65. Id.

66. JGR Acquisitions, a subsidiary of Novell, eventually acquired the patents for $\$ 15.5$ million, winning out over a bid from Intellectual Ventures, a patent holding and licensing firm. Alorie Gilbert, Web Services Patents Fetch \$15.5 Million, CNET NeWS (Dec. 6, 2004, 6:20 PM), http://news.cnet.com/2100-1038_3-5480341.html.

67. See, e.g., ICAP PATENT BROKERAGE, http://icappatentbrokerage.com (last visited Dec. 22, 2012).

68. Todd Bishop, Intellectual Ventures Sues HP, Dell and Others over Patents, GEEKWIRE (July 12, 2011，6:57 AM), http://www.geekwire.com/2011/intellectualventures-sues-hp-dell-patents. 
ting down. ${ }^{69}$ These cautionary tales continue to raise questions about how permanent any particular commitment to defensive patenting can be. ${ }^{70}$ Unless OICs can depend on patents remaining defensive, it is unlikely they will invest in a defensive patent strategy.

From the above analysis, we see at least three substantial barriers to defensive patenting as a strategy for OICs: (1) overly concentrated costs and benefits from patenting, (2) a perceived mismatch between OIC normative values and patenting (and in particular, the patenting of information goods such as software), and (3) a perceived lack of reliability of patent owners to honor existing commitments to use patents defensively. We believe that any defensive patent strategy that will be effective for OICs must address each of these barriers. In the next Part, we discuss these strategic criteria in relation to existing OIC theory and practices, and use the resulting analysis to develop a more detailed framework for effective OIC patent defense strategies.

\section{A FrAMEWORK FOR EVALUATING OIC PATENT STRATEGIES}

Exploring the barriers to defensive patenting, then, helps explain its limited present benefit to OICs. Turning these barriers around, we can identify the following criteria for a viable OIC patent strategy: (1) distributed costs and benefits where the collective benefits outweigh the collective costs, including fiscal, legal, information, and transaction costs; (2) cultural and political alignment with OIC values; and (3) reliable commitments to these values and, importantly, to the use of patents solely for defense. In this Part, we expand upon these criteria in two directions to develop a more detailed framework for discerning what an effective OIC patent defense strategy should look like. First, we examine the broader OIC literature on intellectual property strategies generally, and FOSS literature and licensing practices more specifically. Second, we examine existing OIC patent defense strategies for common values and techniques that have proven acceptable and effective.

69. Chris V. Nicholson, Apple and Microsoft Beat Google for Nortel Patents, N.Y. TIMES DEALBOOK (July 1, 2011, 8:31 PM), http://dealbook.nytimes.com/2011/07/01/apple-andmicrosoft-beat-google-for-nortel-patents.

70. In the world of FOSS copyrights, some of these fears were realized in the SCO v. Linux cases. See Pamela Jones, SCO Litigation: From Soup to Nuts, GroKLAW, http://www.groklaw.net/staticpages/index.php?page=20080803065719599 (last updated Jan. 2, 2011). 


\section{A. Drawing Foundational Principles from the OIC Literature and Practice}

1. OIC Theories, Values, and Practices

The theories, values, and practices of OICs are described in an increasingly robust set of academic literature and practical resources. In this Section, we draw from these resources to identify framework components that address each of the three barriers to defensive patenting we have identified. Two of these barriers - cost-benefit concentration and a lack of reliably defensive patents - each have direct analogues in the FOSS communities' practical methods for addressing copyright issues and organizing production. Addressing the third - a mismatch between patenting and OIC community values and normative theories - requires inquiry into those values and how OIC communities have addressed previous concerns over their mismatch with copyrighting software, eventually adapting and embedding them into production practices.

We begin with OIC community values and organizational theory. In the United States, the dominant theory of intellectual property is based on providing economic incentives through the artificial creation of exclusivity. ${ }^{71}$ Informational goods are by nature non-exclusive, meaning that they generally lack barriers to sharing, ${ }^{72}$ and nonrivalrous, meaning that one person's use does not reduce the enjoyment of the informational good by other users. ${ }^{73}$ Under the dominant theory, legally created exclusivity - in the form of copyrights and patents - creates rivalry and gives competitors an incentive to innovate because they can expect to exploit the exclusivity to recoup their investment, and because others' exclusive rights dictate that they cannot simply copy prior goods without permission and, often, payment. ${ }^{74}$ Without this exclusivity, so the theory goes, firms will be unable to recoup the costs of development and reap profits in the marketplace; therefore, they will lack motivation to innovate. ${ }^{75}$

OICs have long challenged the dominant incentive theory. While individuals, groups, and companies within the different OIC communities have varying viewpoints, all directly reject the need for infor-

71. See William M. Landes \& Richard A. Posner, The Economic Structure of INTELLECTUAL PROPERTY LAW 12-13 (2003).

72. For example, digital copies of software can be copied endlessly with no loss of content and at very little cost.

73. For example, if I tell you my idea for software, we both share and benefit from that idea; its benefits to each of us are undiminished by the telling. See BENKLER, supra note 9, at 36; John P. Conley \& Christopher S. Yoo, Nonrivalry and Price Discrimination in Copyright Economics, 157 U. PA. L. REV. 1801, 1805-06 (2009).

74. Mark A. Lemley, Ex Ante Versus Ex Post Justifications for Intellectual Property, 71 U. CHI. L. REV. 129, 129-31 (2004).

75. LANDES \& POSNER, supra note 71, at 20-21. 
mational exclusivity to provide incentives to create. The FOSS community's viewpoints have been particularly influential. In The Cathedral and the Bazaar, open source pioneer Eric Raymond famously claims that "[e]very good work of software starts by scratching a developer's personal itch," that is, by solving a problem experienced by the programmer. 76 The Free Software Foundation ("FSF") lists multiple motives for writing software, including fun, political idealism, enhancing one's reputation, being admired, making money, and expressing gratitude for others' contributions, ${ }^{77}$ and FSF founder Richard Stallman explicitly states that he is "motivated by an idealistic goal: spreading freedom and cooperation." 78 In recent years, a wide variety of companies and communities have similarly challenged the dominant theory by explicitly following the FOSS model. For example, Joseph Gordon-Levitt's hitRECord online production company, ${ }^{79}$ the 3D printer company MakerBot, ${ }^{80}$ the synthetic biology BioBricks Foundation, ${ }^{81}$ and a wide range of information technology firms have adopted open innovation models for all or some of their products. ${ }^{82}$ Other commentators describe a variety of production models based on motivations other than IP-based exclusivity. ${ }^{83}$ Academic theorist Yochai Benkler points out that the dominant exclusivity theory is drawn from the industrial model of production prevalent in the nineteenth and twentieth centuries, and argues that "non-proprietary strategies have always been more important in information production than they were in the production of steel or automobiles." 84 Benkler agrees with FOSS commentators that motivations go beyond economic incentives based on exclusivity, and argues that other motivations - ranging from benefits to reputation, to the importance of developing know-how, to stimulating demand for a related product

76. ERIC STEVEN RAYMOND, THE CATHEDRAL AND THE BAZAAR 4 (3d ed. 2000).

77. Motives for Writing Free Software, GNU OPERATING SYS., http://www.gnu.org/ philosophy/fs-motives.html (last updated June 10, 2012).

78. Richard Stallman, Copyleft: Pragmatic Idealism, GNU OPERATING SYS., http://www.gnu.org/philosophy/pragmatic.html (last updated June 10, 2012) [hereinafter Stallman, Copyleft].

79. HITRECORD, http://hitrecord.org (last visited Dec. 22, 2012).

80. MAKERBOT, supra note 3.

81. BIOBRICKS FOUND., supra note 4.

82. See BENKLER, supra note 9, at 63-64. For example, Google supports numerous open source projects. Google and the Open Source Developer, GoOGLE, http://code.google.com/ opensource (last visited Dec. 22, 2012). IBM contributes heavily to the development of Linux, the kernel for a free software operating system. See New to Open Source, IBM DEVELOPERWORKS, http://www.ibm.com/developerworks/opensource/newto (last visited Dec. 22, 2012).

83. Dotan Oliar \& Christopher Sprigman, Intellectual Property Norms in Stand-Up Com$e d y$, in MAKING AND UNMAKING OF INTELleCtuAl PROPERTy 385, 385-86 (Mario Biagioli et al. eds., 2011) (discussing how comedians use a system of norms to claim ownership of jokes); Elizabeth Rosenblatt, $A$ Theory of IP's Negative Space, 34 COLUM. J.L. \& ARTS 317, 342 (2011) (discussing non-IP incentives to innovate).

84. BENKLER, supra note 9 , at 4. 
(such as attorney services), and so on - represent a large fraction of the motivations behind information production. ${ }^{85}$

For members of OICs, intellectual property's artificial exclusivity is thus often seen as a barrier rather than a benefit. Copyrights, which make the rights to reproduce, create derivative works, and distribute software exclusive to the copyright holder, and software patents, which make the rights to make, use, sell, import, or offer for sale the software exclusive to the patentee, ${ }^{86}$ severely undermine the expectations and values described by FOSS commentators and embraced by OICs more generally. The programmer who wants to "scratch an itch" is stymied by a prohibition on copying software that might need modification or that provides a needed component for addressing the "itch." With patents, this prohibition is even stricter, prohibiting even independent implementations of particular software methods. For the free software programmer who wants to "spread[] freedom and cooperation," $" 87$ the exclusive rights of intellectual property stymie the ability to develop and share solutions and efficiently cooperate across decentralized networks. ${ }^{88}$ This mismatch between traditional intellectual property theory and the goals of FOSS developers contributes to the most basic norms of the OIC communities: the norms of openness and freedom. OIC leaders often pronounce these norms ${ }^{89}$ in such statements as the FSF's Free Software Definition ("FSD") 90 and the Open Source Initiative's Open Source Definition ("OSD"), ${ }^{91}$ both of which require distribution of source code (openness) ${ }^{92}$ and the freedom to use, modify, and redistribute software for any purpose (freedom) ${ }^{93}$ More recently, other OICs have followed suit. For example,

85. Id. at $44-46$.

86. Alan Devlin, Restricting Experimental Use, 32 HARV. J. L. \& PUB. POL'y 599, 601 n.4 (2009).

87. Stallman, Copyleft, supra note 78.

88. See BENKLER, supra note 9, at 437-39; Greg R. Vetter, Symposium, Commercial Free and Open Source Software: Knowledge Production, Hybrid Appropriability, and Patents, 77 FORDHAM L. REV. 2087, 2094-96 (2009); What is Free Software?, GNU OPERATING SYS., http://www.gnu.org/philosophy/free-sw.html (last updated July 1, 2012).

89. See Bruce Perens, The Open Source Definition, in OPEN SOURCES, supra note 9, at $171,174$.

90. What is Free Software?, supra note 88.

91. The Open Source Definition (Annotated), OPEN SOURCE INITIATIVE, http:// www.opensource.org/osd.html (last visited Dec. 22, 2012).

92. What is Free Software?, supra note 88 (discussing Freedom 1, the freedom "to study how the program works, and change it so it does your computing as you wish"); The Open Source Definition (Annotated), supra note 91, 22 (discussing the Source Code principle).

93. What is Free Software?, supra note 88 (discussing the four essential freedoms of free software); The Open Source Definition (Annotated), supra note 91, §§ 1-3, 5-6, 8-10 (discussing principles of Free Redistribution, Source Code, Derived Works, No Discrimination Against Persons or Groups, No Discrimination Against Fields of Endeavor, License Must Not Be Specific to a Product, License Must Not Restrict Other Software, and License Must Be Technology-Neutral). 
the Open Hardware and Design Alliance lists four freedoms on its home page that approximate the FSF definition. ${ }^{94}$

The norms of freedom and openness find their practical expression in the terms of the standardized software licenses that meet the FSD's or OSD's requirements. The GNU General Public License, Creative Commons licenses for creative works, and the many software licenses that comply with the OSD are examples. ${ }^{95}$ Though they vary considerably in the details, these licenses all grant the rights to use, modify, and redistribute the software they cover (thus supporting the norm of freedom), and require that the human-readable source code be distributed along with the machine-readable compiled code (thus supporting the norm of openness). Therefore, these licenses use the licensor's copyright rights - and in some cases, contract law ${ }^{96}-$ to allow and enforce openness and freedom. Further, the licenses themselves are all transparent and publicly available - anyone can review the terms, at any time - further supporting the norm of openness. ${ }^{97}$

The method of using standardized copyright licenses to encourage and enforce OIC values and norms also operates to lower and decentralize the costs of production and to distribute the benefits across the entire OIC community. At one level, the standardized nature of the licenses reduces the fiscal and legal resources required to develop and apply the license - writing a standardized license limits these costs to the initial drafting and periodic updates, as everyone in the community simply uses the form license when distributing code. ${ }^{98}$ This method also drastically lowers the informational and transactional costs of licensing - the terms are standard and transparent to all parties, so there is no information asymmetry and no need to negotiate terms. This reinforces openness at both the legal layer and the code layer. At the next level, open licenses allow for the decentralized production of software and other informational goods. Because the intellectual property rights are standard, and freedom to modify is included in these open licenses, anyone can contribute to a project without worrying about licensing rights - lowering production costs and generating positive network effects that can enhance production speed and quali-

94. Open Source Hardware \& Design Alliance, supra note 2 (detailing the "4 Freedoms").

95. See, e.g., Open Source Licenses, OPEN SOURCE INITIATIVE, http:// www.opensource.org/licenses/index.html (last visited Dec. 22, 2012).

96. See Robert W. Gomulkiewicz, Enforcement of Open Source Software Licenses: The MDY Trio's Inconvenient Complications, 14 YALE J.L. \& TECH. 106, 125 (2011).

97. See Open Source Licenses, supra note 95 (listing open source licenses).

98. See The GNU General Public License v3.0, supra note 22 ("Everyone is permitted to copy and distribute verbatim copies of this license document, but changing it is not allowed."). 
ty. ${ }^{99}$ Finally, the right to use or modify the software is available to anyone, fully distributing the benefits as part of the norm of freedom.

Finally, FOSS licenses provide reliability to OIC communities. Because the community's norms are reflected in the licenses' requirements, they are seen as legally enforceable, ${ }^{100}$ and thereby reliable. A FOSS developer knows that the source code needed to understand and modify a product must be included with the compiled code because the license requires it. Communities that support "copyleft" principles go further, and use licenses to create reliable sharing requirements. A copyleft license not only allows modification and requires that the source code be available, it also requires that any modifications be distributed under the same license, making the freedom and openness requirements "viral."101 The GNU General Public License and the Creative Commons Share-Alike licenses are the canonical examples. By conditioning the license terms upon the licensee's commitment to freedom and openness, copyleft OICs can ensure that, as the network of users grows, new users enhance the value of the network through ongoing commitments to the same principles and norms. This fosters reliability by creating enforceable norms and limits gamesmanship. Creating a legal requirement to share, via the copyright license, is the mechanism the copyleft FOSS communities use to ensure that a software project, and any distribution based on it, remains reliably open and free. As the FSF states: "If middlemen could strip off the freedom, we might have many users, but those users would not have freedom .... Copyleft guarantees that every user has freedom." 102

99. See BENKLER, supra note 9, at 66-67.

100. It was not always clear how robust FOSS and Creative Commons licensing models would be for users. Some commentators argued that the licenses were likely to be practically or legally unenforceable. See Jennifer M. Urban, Legal Uncertainty in Free and Open Source Software and the Political Response, in THE POLITICS OF OPEN SOURCE ADOPTION 69, 72-74 (Joe Karaganis \& Robert Latham eds., 2005), available at http:// wikis.ssrc.org/posa/images/POSA1.0.pdf. However, OIC licenses have now been enforced in a handful of court cases. See, e.g., Jacobsen v. Katzer, 535 F.3d 1373, 1382-83 (Fed. Cir. 2008). Perhaps more importantly, the licenses undergird a sufficiently large amount of production that they serve to organize the norms of FOSS and other OIC projects, limiting the need for court challenges. Therefore, the licenses' expression of norms appropriate to OICs may be their most important role. Cf. Cass R. Sunstein, On the Expressive Functions of Law, 144 U. PA. L. REV. 2021, 2024-25 (1996) (arguing that law can signal information about social norms and appropriate conduct to citizens).

101. See Frequently Asked Questions, OPEN SOURCE INITIATIVE, http://opensource.org/ faq\#copyleft (last visited Dec. 22, 2012); Share Alike, CREATIVE COMMONS, http://wiki.creativecommons.org/Share_Alike (last visited Dec. 22, 2012); What is Copyleft?, GNU OPERATING SYS., http://www.gnu.org/copyleft/copyleft.html (last updated June 10, 2012).

102. What is Copyleft?, supra note 101. 


\section{Principles Derived from OIC Theory, Values, and Practices}

The theory and practice behind OICs, especially FOSS communities, give us several principles and methodologies to draw upon in considering how to overcome barriers to designing an effective framework for OIC patent defense.

\section{A. Principle One: Commitment to Freedom}

\section{i. Freedom to Operate and Freedom to Innovate}

The first and foremost normative principle in OICs is freedom, enforced by cultural expectations and licensing regimes. Specifically, most OIC norms support two types of freedom: freedom to operate and freedom to innovate. Freedom to operate, a term most often used in the patent world, means a general freedom from intellectual property limitations to make, use, sell, import, or offer for sale a particular device or service. ${ }^{103}$ For most FOSS copyright licenses, this concept translates to the freedom to run the program for any purpose, and the freedom to study how the program works. The freedom to innovate extends this to include the freedom to change the software to make it do what you wish, ${ }^{104}$ including the freedom to modify and redistribute the software. ${ }^{105}$

In the realm of patents, we believe the same principles should be supported. The freedoms to operate and innovate benefit OICs by encouraging collaboration, lowering barriers to entry, and generally making technological innovations more accessible. Interestingly and importantly, the right to modify in copyright is specifically granted to copyright owners via the derivative work right; ${ }^{106}$ however, in patent law, studying inventions and innovating on top of them is generally not an exclusive right. ${ }^{107}$ Thus, in some ways, patent law is more initially amenable to this second freedom than copyright.

103. See What Does "Freedom to Operate" Mean?, PATENT LENS, http://www.patentlens.net/daisy/patentlens/2768.html (last visited Dec. 22, 2012).

104. What is Free Software?, supra note 88.

105. Id.; see also OPEN SOURCE HARDWARE \& DESIGN AlLIANCE, supra note 2.

106. See 17 U.S.C. § 106(2) (2006).

107. Peter Lee, The Accession Insight and Patent Infringement Remedies, $110 \mathrm{MicH}$. L. REV. 175, 227 n.333 (2011) ("[C]opyright law operates differently than patent law by vesting exclusive rights to 'derivative works' in the original copyright holder."); see also Henrik Holzapfel \& Joshua Sarnoff, A Cross-Atlantic Dialog on Experimental Use and Research Tools, 48 IDEA 123, 123-24 (2008) (discussing the scope of the experimental use exception). 


\section{B. Principle Two: Commitment to Openness}

A second principle of OIC culture is openness. Openness primarily refers to access to sufficient knowledge about an information good to understand it and to share that information with others as desired; however, it can also mean transparency of the legal regime governing the good.

\section{i. Access to Knowledge}

The first component of openness is meaningful access to knowledge about the information good. The primary means by which OICs commit to this component of openness is by sharing the basic building blocks of the technology and then enforcing that sharing via open licenses. For example, in software, the shared building blocks primarily consist of the source code; in hardware, the schematics that describe the hardware; in biology, the genetic sequences that make up an innovative compound; and so on. ${ }^{108}$

For OIC patent strategies, access to knowledge is an essential normative requirement. Permission to use patented technology without full information about the technology's characteristics would undermine this principle. In fact, patent law purports to serve this exact purpose - disclosure of knowledge about the invention - as the quid pro quo for exclusivity. ${ }^{109}$ However, some commentators argue that under current patent law, this goal has been undermined by several doctrines; chief among these are the danger of additional willful infringement damages that may stem from reading patents that may cover one's product ${ }^{110}$ and the generally weak enforcement of the written description and enablement requirements, ${ }^{111}$ which are intended to serve as mechanisms for ensuring robust disclosures. ${ }^{112}$ That said, were innovators encouraged to read patents rather than avoid them, and were the written description and enablement requirements

\footnotetext{
108. See, e.g., REgISTRY OF STANDARD BIOLOGICAL PARTS, http://partsregistry.org/Main_Page (last visited Dec. 22, 2012) (a collection of genetic parts); SOURCEFORGE, http://sourceforge.net (last visited Dec. 22, 2012) (a source code repository of FOSS projects); THINGIVERSE, http://www.thingiverse.com (last visited Dec. $22,2012)$ (a repository of digital designs of physical objects).

109. See 35 U.S.C. $\$ 112$ (2006 \& Supp. V 2011), amended by Leahy-Smith America Invents Act, Pub. L. No. 112-29, § 15, 125 Stat. 284, 328-29; In re Donaldson Co., 16 F.3d 1189,1195 (Fed. Cir. 1994) (en banc) (invalidating patent for insufficient disclosure).

110. See, e.g., Mark A. Lemley, Ignoring Patents, 2008 Mich. ST. L. REV. 19, 21 (2008).

111. Stuart J.H. Graham \& Ted Sichelman, Symposium, Why Do Start-Ups Patent?, 23 BERKELEY TECH. L.J. 1063, 1088 (2008).

112. Until recently, there was also a "best mode" disclosure requirement. See LeahySmith America Invents Act $\S 15$ (eliminating the "best mode" requirement); Memorandum from Robert W. Bahr, Senior Patent Council, U.S. Patent \& Trademark Office on Requirement for a Disclosure of the Best Mode to Patent Examining Corps (Sept. 20, 2011), available at $\mathrm{http} / / / \mathrm{www} . u s p t o . g o v / a i a \_i m p l e m e n t a t i o n /$ best-mode-memo.pdf.
} 
to be faithfully fulfilled, patent law could in fact reinforce and supply much of the open access to knowledge that OICs support. Thus, any OIC patent strategy should devote some effort to shoring up the openness of patents and increase the amount of disclosure they provide, as well as providing full access to the patented technology itself and to the related source code, schematics, or other descriptive information.

\section{ii. Transparent and Non-Discriminatory Legal Terms and Enforcement Conditions}

The second aspect of OIC openness moves beyond the technology itself to the transparency and non-discriminatory nature of the legal terms and enforcement conditions of standardized OIC licenses. The openness of OIC licenses allows every member of an OIC to read, understand, and evaluate the legal instruments used to enforce OIC norms. Broad publication and replication of OIC licenses removes the need for individualized license negotiations, thus encouraging the use of OIC technologies and participation in the community by lowering individual information and transactional costs. ${ }^{113}$ Open licensing also facilitates trust and accountability among OICs by providing a common set of legal commitments that can be tested both in court and in public discourse. Additionally, open licensing can reinforce various non-monetary community norms, such as sharing and collaboration, by requiring the general inclusion of authorship information. ${ }^{114}$ Thus, any OIC patent defense strategy should also provide similar legal transparency and non-discrimination.

\section{iii. Interoperability and Technology Neutrality}

The third and fourth aspects of openness are interoperability and technology neutrality. Because these two aspects of openness go hand-in-hand, we have grouped them together. Interoperability is a design principle that encourages technologies to allow interaction with other technologies. ${ }^{115}$ In this sense, "open" means both transparent and accessible to others who might want to interact and build upon the technology. When successful, interoperability can create network effects that increase the value of any given OIC input to every other aspect of the system. For example, allowing a technology to work with many different operating systems, keyboards, monitors, or mobile devices ensures that the technology has the greatest potential for

113. See The Open Source Definition (Annotated), supra note $91, \S 5$.

114. E.g., Attribution 3.0 Unported (CC BY 3.0), CREATIVE COMmons, $\mathrm{http} / / /$ creativecommons.org/licenses/by/3.0 (last visited Oct. 26, 2012) (requiring attribution in the manner specified by the author or licensor of the original work).

115. See Hiram Meléndez-Juarbe, DRM Interoperability, 15 B.U. J. SCI. \& TECH. L. 181, 188 (2009). 
increasing social welfare, and allows for robust competition among a range of aftermarket options. ${ }^{116}$

Technology neutrality is a related concept that is generally understood as a principle of non-discrimination. ${ }^{117}$ The OSD addresses technology neutrality with a simple rule: "No provision of the license may be predicated on any individual technology or style of interface." 118 In other words, the OSD prohibits an innovator from granting license rights only to those who use some forms of technology and not others; rather, the license rights must apply to all technologies. This ensures that OIC technologies cannot foreclose competing or new technologies, thus maximizing access and enhancing network effects.

\section{Principle Three: Distributed Costs and Benefits}

A third principle focuses on the distribution of innovation costs and benefits. In order to encourage the production of OIC goods through the use of decentralized networks, OICs emphasize mechanisms that will distribute both the costs and benefits of production across the network; this is the foundation of most OICs' ongoing efforts to take advantage of positive network effects to fuel further innovation and production. ${ }^{119}$ In order for this distribution to happen efficiently, technological production, distribution, use, and innovation in OICs must scale easily as the network grows. Both Principle One and Principle Two are foundational to creating these positive effects. Taken together, freedom to operate, freedom to innovate, access to knowledge, transparent and non-discriminatory legal instruments, and interoperability and technology neutrality mean that every participant can both reap the benefits of each new production and contribute indi-

116. See Pamela Samuelson \& Suzanne Scotchmer, The Law and Economics of Reverse Engineering, 111 YALE L.J. 1575, 1616, 1622 (2002) (discussing the competition benefits of open architectures and the reduction in development costs attributable to open interfaces).

117. Marcelo Thompson, The Neutralization of Harmony: The Problem of Technological Neutrality, East and West, 18 B.U. J. SCI. \& TECH. L. (2012), available at http://ssrn.com/abstract=1936067; see also BARBARA VAN SCHEWICK, INTERNET ARCHITECTURE AND INNOVATION 220 (2010) (outlining non-discrimination in network neutrality).

118. See The Open Source Definition (Annotated), supra note 91, §10; see also id. §6 ("No Discrimination Against Fields of Endeavor"); id. $§ 8$ ("License Must Not Be Specific to a Product").

119. Positive network effects are economic externalities that benefit every other component of a network with each additional option or input to the network. A common example is the telephone network. Every time an additional phone is added to the network, the network is more valuable to each user because she now has one more resource she can access via the network. In the OIC context, innovation and production can occur ever more efficiently as more innovators enter a project and contribute to it. Both freedom and openness operate to lower the barriers to entry for new innovators, generating positive network effects. 
vidually to any task. The network also benefits as a whole from the distribution of costs among the participants.

\section{Principle Four: Reliability}

Ensuring the reliability of the normative commitments to freedom, openness, and distributed benefits is another key OIC principle, especially in communities that operate on volunteer or other nonmonetary bases. Reliability arises from both the community's informal policing of norms and from the intellectual property licensing structures that enforce key requirements for the communities. Together, these enforcement structures help convince OIC members to participate in open innovation processes by building in trust and accountability, providing assurances that their contributions will remain subject to the normative commitments that the OIC values. ${ }^{120}$ Specifically, there appear to be at least two separate characteristics of reliability critical for OIC functionality: longevity and robustness.

\section{i. Longevity}

The first characteristic of reliability is longevity. Simply put, the normative commitments need to last. If they were to expire or be abandoned after only a short period, their associated benefits to the community could be severely limited, both in terms of their intrinsic value and their potential for scalability. The use of standardized intellectual property licenses to enforce norms accomplishes this through the term of the exclusive rights at issue. In most countries, copyright entitlements last at least fifty years and often far longer; patent terms, at twenty years, are shorter but are similar with regard to their ability to enforce norms over a sustained period of time. ${ }^{121}$ Thus, intellectual property can serve a positive role in creating longevity if it can be employed as a norm enforcer instead of a norm adversary.

\section{ii. Robustness}

The second characteristic of reliability is robustness - the ability of the open innovation regime to withstand challenges and attempts to "game" the system. OICs vary in their tolerance for different uses of

120. See Robert W. Gomulkiewicz, Open Source License Proliferation: Helpful Diversity or Hopeless Confusion?, 30 WASH. U. J.L. \& POL'Y 261, 266 n.32 (2009) (describing a "nexus of trust").

121. Cheryl W. Gray \& William W. Jarosz, Law and Regulation of Foreign Direct Investment: The Experience from Central and Eastern Europe, 33 COLUM. J. TRANSNAT'L L. 1, 23 (1995) (detailing the international norms of copyright and patent term duration). 
open innovation systems. For example, the open source wing ${ }^{122}$ of the FOSS community is quite comfortable with the idea that firms might take open source code and embed it into a closed, proprietary system, thus internalizing the benefits, ${ }^{123}$ while the free software wing considers distributive sharing a foundational component of freedom. ${ }^{124}$ However, all desire to avoid the subversion of the community's normative principles and distributed organization. ${ }^{125}$

With regard to patents, norm-undermining gamesmanship by patent holders is a significant concern for OICs. ${ }^{126}$ In the copyright context, licensing requirements - particularly copyleft-style requirerequirements - are used by OICs to reduce gamesmanship. As we describe further in Part IV, we think the licensing methodologies used to enhance reliability in the copyright context can be applied to OIC patent strategies as well.

\section{B. Existing OIC Patent Defense Strategies}

Having examined the theory, values, and practices of OICs regarding copyrights, we now turn to how they have approached the issue of patents. OICs have been concerned about patent threats for some years, and various existing proposals and methods for dealing with problematic patents presently exist. The most prominent strategies include: (1) defensively publishing information to serve as invalidating prior art against subsequent patent applications on the same technology, ${ }^{127}$ (2) encouraging patent pledges in which patent holders promise not to enforce against OIC actors, ${ }^{128}$ (3) inserting so-called "patent peace provisions" into open source licenses that obligate li-

122. We are loosely defining the "open source" community as those who are opposed to the free software insistence on "copyleft" requirements.

123. For leaders in the open source community, the ability to internalize such benefits is seen as an important component of freedom. See Perens, supra note 89, at 183 (discussing the ability to take modifications private under the $\mathrm{X}$ license).

124. See Philosophy of the GNU Project, GNU OPERATING SYS., http:// www.gnu.org/philosophy (last visited Dec. 22, 2012).

125. An example of the FOSS community's interest in preventing this kind of gamesmanship is the controversy surrounding the long-running Unix-SCO litigation. See Jones, supra note 70.

126. See, e.g., Michael Weinberg, It Will Be Awesome IF They Don't Screw It Up: 3D Printing, Intellectual Property, AND the Fight Over the NeXt Great DISRUPTIVE TECHNOLOGY 12 (2010), available at http://www.publicknowledge.org/files/ docs/3DPrintingPaperPublicKnowledge.pdf (forecasting the rise of patent "skirmishes" in 3D printing); Roger Parloff, Microsoft Takes on the Free World, CNNMONEY (May 14, 2007), http://money.cnn.com/magazines/fortune/fortune_archive/2007/05/28/100033867.

127. See, e.g., Defensive Publications, LINUX DEFENDERS, http://linuxdefenders.org/ projects?tab=3 (last visited Dec. 22, 2012).

128. See, e.g., IBM Statement of Non-Assertion of Named Patents Against OSS, IBM, http://www.ibm.com/ibm/licensing/patents/pledgedpatents.pdf (last visited Dec. 22, 2012) [hereinafter IBM Statement]; Red Hat, Inc.: Statement of Position and Our Promise on Software Patents, RED HAT, http://www.redhat.com/legal/patent_policy.html (last visited Dec. 22, 2012) [hereinafter Red Hat Statement]. 
censees to avoid patent conflicts within code contributors, ${ }^{129}$ and (4) forming patent protection "watchdog" groups that collect pools of patents to assert against offensive threats to the community. ${ }^{130}$ In this Section, we examine these strategies in order to extrapolate further principles and means to draw upon in evaluating and optimizing defensive patent strategies.

\section{Defensive Publication}

Defensive publication, rather than focusing on obtaining patents for direct defensive use against lawsuits, instead focuses on creating a bulwark against future patent threats by publishing information about OIC technologies in order to create prior art against future patent grants that would cover the technology. This works because, when knowledge is publicly disclosed under the patent laws, no future patent application generally can be granted as to the knowledge contained within the prior art or any obvious improvement thereupon. ${ }^{131}$

Defensive publication takes advantage of many of the underlying principles that OICs already employ. For example, because one of the core commitments of openness is access to knowledge, publishing technical information within OICs is generally prolific and consistent with this value. It is also generally low-cost and distributed, as many OICs use public repositories to store their code and communications. ${ }^{132}$ The benefits are also distributed, as preventing patents protects all OIC members from threats. It also reflects OIC cultural and political expectations by strongly promoting access to knowledge, freedom to operate, and freedom to innovate. And because the information is in the public domain, defensive publication promotes technology neutrality and interoperability.

Defensive publication has, however, some important limitations. As a practical matter, merely publishing the information is necessary but not sufficient for it to serve as prior art. In order for information to be effective as prior art, it must be publicly accessible and patent examiners and courts must learn about it. ${ }^{133}$ Thus, search and information costs can create barriers to effectiveness. This has inspired numerous attempts to build systems, search engines, and repositories

129. See, e.g., Yahoo! DomainKeys Patent License Agreement v1.2, § 3.1, DomainKeYs, http://domainkeys.sourceforge.net/license/patentlicense1-2.html (last visited Dec. 22, 2012).

130. See, e.g., About OIN, OPEN INVENTION NETWORK, http:// www.openinventionnetwork.com/about.php (last visited Dec. 22, 2012).

131. 35 U.S.C. $\S \S 102-03$ (2006 \& Supp. V 2011), amended by Leahy-Smith America Invents Act, Pub. L. No. 112-29, §§ 3, 20, 125 Stat. 284, 285-93, 333-35.

132. See, e.g., About, SOURCEFORGE, http://sourceforge.net/about (last visited Dec. 22, 2012); see also Audris Mockus et al., A Case Study of Open Source Software Development: The Apache Server, PROC. OF THE 22ND INT'L CONF. ON SOFTWARE ENGINEERING 1 (2000), available at $\mathrm{http} / / /$ ifipwg213.org/system/files/mockusapache.pdf.

133. See In re Hall, 781 F.2d 897, 898-99 (Fed. Cir. 1986). 
for prior art to help lower the search, information, and transaction costs in finding published information for both the USPTO and patent litigation defense lawyers. ${ }^{134}$

In addition, despite the theoretically low cost of publishing information online, the majority of defensive publishing efforts have failed to provide scalable patent defense for OICs. We posit that this is for two reasons. First, while OICs generate prolific amounts of technical information, they do not automatically organize their information in ways that speak to the needs of patent examiners, judges, or juries; instead (and understandably), they organize it in ways that speak to engineers. So, for example, an OIC code base will include the code and occasionally documentation or commentary meant for engineers to understand how to implement and fix it, what bugs are currently within it, and what new features might be in the offing. ${ }^{135}$ The basics of how the code is designed and how it operates will likely be assumed or glossed over because the code works. Yet this is exactly the information that patent examiners, judges, and juries need to reject claims or invalidate patents. They need basic explanations that describe the broad functionality and potential (and even hypothetical) applications of the technology. They also often need the information described in a manner they can understand if they are not trained in the specific technology or discipline of the publisher.

Second, because patent attorneys are well aware that defensive publication could thwart their clients' desire for patents, they will often attempt to characterize patent claims in words other than those a traditional engineer or innovator in the field would use. It is black letter patent law that a patentee may be "his own lexicographer"136 and thus use any words he wants - even made-up words that he invents - to describe his invention. So instead of describing a children's slide as a "slide," he may describe it as "an elongated trough" with a "substantially straight traverse cross-section." 137 This is commonplace as a strategy to avoid prior art, and makes it difficult for engineers and other non-lawyers to develop effective prior art data-

\footnotetext{
134. See, e.g., Do TAnK, PeER to PAtent: The Community Patent Review Project, available at http://dotank.nyls.edu/communitypatent/docs/info/P2P_Brochure.pdf; DEFENSIVE PUBLICATIONS, http://www.defensivepublications.org (last visited Dec. 22, 2012); How it Works, ARTICLE ONE PARTNERS, http:// www.articleonepartners.com/how-it-works (last visited Dec. 22, 2012); PUBLIC DOMAIN IDEAS, http://www.publicdomainideas.org/index.php/Main_Page (last updated Sept. 13, 2012).

135. Cf. Why Free Software Needs Free Documentation, GNU OPERATING SYS., http://www.gnu.org/philosophy/free-doc.html (last updated May 18, 2012) (emphasizing the importance of documentation as an "essential part of any software package").

136. See U.S. PATENT \& TRAdEMARK OfFice, Manual of PATENT Examining PROCEDURE $\S 2111$ (8th ed. 2001), available at http://www.uspto.gov/web/offices/pac/ mpep/s2111.html.

137. U.S. Patent No. 5,842,927 (filed Dec. 1, 1998).
} 
bases that rely on Boolean or linguistic searches to match art to patent claims. Moreover, when the prior art is merely the distribution of OIC source code, searching the code for prior art would be especially difficult.

Thus, while defensive publication provides possibly the most distributed benefits of any OIC patent strategy - i.e., the entire world benefits from access to the knowledge published and its ability to invalidate any patent claim that attempts to cover the published technology - the search and information costs associated with finding the right defensive publication limit the benefits of the strategy as a practical matter. ${ }^{138}$ Therefore, it is a partial strategy. A more optimal patent strategy would provide the same benefits to all OICs and at the same time attempt to lower costs, especially in the search, information, and transactional areas.

In terms of longevity and robustness, defensive publication also presents some challenges. Longevity requires that the information be available and accessible when needed to defend against a patent application or claim. Therefore, beyond the cost of producing the information, it must be organized and maintained in a manner that reduces the search, information, and transaction costs of decision-makers and advocates. Because patent examiners have, on average, only eight to eighteen hours to complete the review work for each patent, ${ }^{139}$ if they do not find the most relevant art immediately, it may not become a factor in the examination. Finally, current public search engines such as Google often discount older information in favor of new, creating further questions about the effectiveness of many defensive publications as the search costs required to find them go up over time.

With regard to robustness, the ability to "game" defensive publication varies, depending on how well defensive publications can be mapped to subsequent patent claims intended to cover the same invention. Defensive publications face at least two challenges to their effectiveness here. First, as noted above, there is an inherent linguistic problem in predictably mapping publications written for engineers to patents written for examiners, judges, and juries. Second, patent attorneys are skilled at playing linguistic games with claim language that make the claims appear different from the invention disclosed in relevant publications. Prior art in the form of patents, on the other hand, suffers less from this problem because patents are generally written for the same audience and often describe inventions broadly, explicitly, and with numerous examples.

138. It is worth noting that crowdsourcing prior art projects such as Peer to Patent attempt to mitigate this problem by calling on expert communities to contextualize and annotate prior art so that examiners can understand that different terms may describe similar technologies. See Do TANK, supra note 134.

139. See Mark A. Lemley, Rational Ignorance at the Patent Office, 95 Nw. U. L. REV. $1495,1500,1500$ n.19 (2001). 


\section{Patent Pledges}

Patent pledges are promises by patent holders not to enforce their patents under certain conditions. In legal terms, the mechanism by which this takes effect is either estoppel (for those who can show reliance on the pledge) or implied license (for those who lawfully acquire and utilize the technology covered by the patents). Among OICs, Red Hat has provided one of the boldest and most prominent examples of such a pledge, promising not to assert any Red Hat patent claim against any use of FOSS. ${ }^{140}$ IBM, Nike, the BioBricks Foundation, and others have made similar pledges for various OICs. ${ }^{141}$ To date, no such pledge has been tested in court.

Patent pledges appear to offer their benefits in a distributed manner to a particular OIC population, for example, Red Hat's offer is to the FOSS community. However, for any individual member of an OIC to receive an explicit legal benefit from a pledge, she must demonstrate some reliance on, or implied acceptance of, the pledge. Thus, it is unclear how broadly these benefits extend because there is no known record of who has specifically relied on each pledge. In addition, pledges require no reciprocal agreement to keep technology open - for example, a company may rely on a pledge to produce software but make no pledge of its own as to patents that cover that software, reintroducing the patent liability risk to downstream innovators.

Beyond these limitations, there is also the problem of pledge size and scope. While the Red Hat pledge makes non-enforcement promises as to all patents, it does so only as to the use of FOSS, leaving aside, for example, hardware that might be offered under an open license yet run on proprietary software. ${ }^{142}$ And Red Hat's pledge is comparatively broad. IBM's pledge, which is directed to open source software (as defined by the OSD) is far narrower, mentioning only

140. See Red Hat Statement, supra note 128.

141. See The BioBrick Public Agreement, BIOBRICKS FOUND., https://biobricks.org/bpa (last visited Dec. 22, 2012); IBM Statement, supra note 128; THE PATENT PLEDGE, http://thepatentpledge.org (last visited Dec. 22, 2012); Kaitlin Thaney, GreenXchange - A Project of Creative Commons, Nike and Best Buy, CREATIVE COMMONS (Feb. 10, 2009), http://creativecommons.org/weblog/entry/12734 (noting that the GreenXchange draws on the experience of Creative Commons in creating "some rights reserved" regimes for artists, musicians, scientists, and educators, as well as patent "commons" projects like the Linux Patent Commons, the BIOS project, FreePatentsOnline and the Eco-Patent Commons).

142. From Red Hat's patent pledge:

Our Promise does not extend to any software which is not Open Source/Free Software, and any party exercising a Patent Right with respect to non-Open Source/Free Software which reads on any claims of any patent held by Red Hat must obtain a license for the exercise of such rights from Red Hat.... No hardware per se is licensed hereunder.

Red Hat Statement, supra note 128. 
specific patents. ${ }^{143}$ This has led to some uncertainty about the pledge's scope, and concerns that IBM's pledge includes meaningless "junk" patents instead of the more valuable "crown jewel" patents that might pose a more direct threat of litigation. The worry is that IBM may control via patent the most marketable or otherwise valuable aspects of Linux, which it cannot control via copyright due to the GPL's copyleft terms. ${ }^{144}$ Similar critiques can be made about other pledges, notably the Eco-Patent Commons and the Creative Commons GreenXchange approaches, which also provide pledges or licenses only on a patent-by-patent basis, leaving out some important portfolios and leaving the supposed beneficiaries with extensive search and information costs if they want to make sure that they have freedom to operate. ${ }^{145}$ This fails to maximize benefits under the criteria of technology neutrality and interoperability.

Patent pledges - while they theoretically distribute benefits to anyone who chooses to rely on them - are also limited in their ability to fully distribute costs and benefits. First, the pledge model concentrates the costs within specific companies that already have significant patent portfolios without requiring any of the beneficiaries of the pledges to bear similar costs. They are not distributed in the same way that knowledge, technology, and licenses are distributed in OICs more generally. Second, because there is no reciprocal or viral component to the pledge, this strategy does not take advantage of positive network effects to extend the benefits and costs within the network or encourage those outside OICs to join and grow the network. By limiting the pledges to specific patents and specific OICs rather than covering open technologies more generally, firms that use this strategy fail to distribute both the costs and benefits as widely as possible.

In many instances, patent pledges represent the attempts of large actors, such as IBM, to meet OIC cultural expectations and allay fears of patent threats from companies that see a strategic value to entering the OIC space but have not previously used open innovation as a model. In practical terms, patent pledges do provide some assurance of freedom and openness. At the same time, as noted above, they are limited in terms of their ability to support expectations of technology neutrality and interoperability by the common feature of restricting

143. Jim Zemlin, IBM's Open Source Patent Pledge, LinUX Found. (Apr. 7, 2010, 5:44 PM), http://www.linuxfoundation.org/news-media/blogs/browse $/ 2010 / 04 / \mathrm{ibm} \% \mathrm{E} 2 \% 80 \%$ 99s-open-source-patent-pledge.

144. See New to Linux Programming and Linux System Administration, IBM DEVELOPERWORKS, http://www.ibm.com/developerworks/linux/newto (last visited Dec. 22, 2012) (describing the use of the GPL).

145. Eco-Patent Commons: Joining or Submitting Additional Patents to the Commons, WORLD BUS. COUNCIL FOR SUSTAINABLE DEV., http://www.wbcsd.org/web/projects/ ecopatent/EcoPatentGroundRules.pdf (last visited Dec. 22, 2012); About the GreenXchange, GREENXCHANGE, http://greenxchange.cc/info/about (last visited Dec. 22, 2012) (specifying that users can post assets from their portfolios). 
the protection to specific OICs. Further, even for pledges offered by a member of an OIC, there has been some tension as to the exact commitment embedded within each pledge, especially as there is no standardized legal language for OIC pledges. ${ }^{146}$

Beyond their limited reach in practice, a lack of perceived reliability is likely the greatest limitation on pledges' ability to alleviate patent concerns in OICs. Patent pledges are generally quite transparent in their terms. Further, in theory, they last for the full duration of the relevant patent terms, so the longevity criterion seems to be satisfied. However, their level of robustness raises concerns. First, because pledges rely on the legal doctrines of estoppel and implied license, they are susceptible to attack while they are in effect. Estoppel is a fact-specific defense to infringement in which an alleged infringer must show that she knew of the patentee's promise and then materially and reasonably relied upon it. ${ }^{147}$ Implied license requires a strong showing of the patentee's intent to license for a specific use (as opposed to a more general set of permissions); further, the license can be withdrawn under many circumstances, such as when there is no explicit consideration in return for the product. ${ }^{148}$ Therefore, reliance on an extant patent pledge carries uncertainty.

Second, patent pledges are entirely under the control of the pledging entity, which can choose to withdraw them at any time, leaving stranded anyone who cannot already show reliance or active, specific uses. Therefore, an entity that pledges important patents can, in theory, strategically withdraw its pledge once a technology becomes central to a network or otherwise especially valuable. ${ }^{149}$ And even if a pledging firm remains committed to its initial strategic decision to pledge patents, the pledged patents may later be sold to entities, including trolls, that did not make similar promises. ${ }^{150}$

Given these limitations, it is unclear that pledges will produce broad-based reliability for OICs with regard to patent threats. However, harnessing the benefits of pledges - especially their transparency and inexpensive applicability to all who are engaged in innovation

\footnotetext{
146. Compare Red Hat Statement, supra note 128, with IBM Statement, supra note 128.

147. For an argument to make the estoppel doctrine more robust in the realm of technical standards, see Robert P. Merges \& Jeffrey M. Kuhn, An Estoppel Doctrine for Patented Standards, 97 CALIF. L. REV. 1, 30 (2009).

148. See Joe Mutschelknaus, Spillover Effect: Investigating Patent Implications to OpenSource Software Copyright Licensing, 19 FED. CIRCUIT B.J. 409, 428-29 (2009) (arguing that a patentee cannot revoke an implied patent license when consideration is received).

149. This likelihood is no doubt limited by the damage a firm would incur to its reputation by taking such an action. Further, to some extent, OICs can do what they do best design around the issue - but this response is limited in effectiveness when the patents in question are sufficiently broad. It is a more effective response in the copyright realm, where threatened code can be rewritten to overcome the more narrowly construed copyright protection.
}

150. Bankruptcy is a particular concern. See supra notes 64-66 and accompanying text. 
covered by the pledge - to a strategy that provides more reliability would increase robustness. As we will discuss in Part IV, this can be accomplished through more explicit assent, commitment, and accountability mechanisms that rely on legal doctrines with lower burdens on OIC users, obligations to enforce the commitment as to successors-in-interest, and limiting the ability of pledging firms to engage in gamesmanship by offering only some relevant patents under the pledge.

\section{Patent "Peace" Provisions}

Patent "peace" provisions are specific terms in OIC licenses that require any licensee of the OIC technology to forgo patent lawsuits against the licensor and, in some forms, other licensees or users of the same OIC technology. The most famous example of the latter is Section 10 of Version 3.0 of the GPL ("GPLv3"), which terminates the GPL's copyright license, along with any patent licenses, in the event that a user initiates a patent lawsuit against a contributor to any GPLv3 licensed program. ${ }^{151}$ Peace provisions are structured as legally binding commitments, either as a general covenant not to sue or as a specific license to a particular OIC technology. ${ }^{152}$ Other examples include the Apache license ${ }^{153}$ and the Yahoo! DomainKeys license. ${ }^{154}$

Patent peace provisions provide the distributed benefit of safety from patent threats from known OIC licensees, which promote access to knowledge of the OIC technology and freedom to operate and innovate. The scope of the benefit varies based on the size and power of licensee patent portfolios and whether the covenant not to sue covers just the licensor or all users of the OIC technology. The costs are similarly distributed within the network of license users, although one might assume that the relevant costs of patent acquisition and enforcement are concentrated among the larger entities with internal patent-related legal resources.

However, much like the patent pledge model, there is a limit to the scale of this model. Because the benefits are limited to users of the license or technology at issue, patent peace provisions do not provide any structures or incentives to grow the network and maximize the positive network effects of the defensive practice. Nor do they emphasize technology neutrality or interoperability with other OIC technol-

151. See The GNU General Public License v3.0, supra note 22.

152. For example, Google offers a product-specific license to any patents that cover the WebM VP8 video codec, which is part of the WebM open media platform. See Additional IP Rights Grant (Patents), WEBMPROJECT.ORG, http:/www.webmproject.org/license/ additional (last visited Dec. 22, 2012).

153. Apache License, Version 2.0, APACHE SOFTWARE FOUND. (Jan. 2004), http://www.apache.org/licenses/LICENSE-2.0.

154. Yahoo! DomainKeys Patent License Agreement v1.2, supra note 129. 
ogies. Thus, the costs and benefits, while distributed to various extents, are still relatively limited in both scope and potential.

Patent peace provisions also meet cultural and political expectations in similar ways to patent pledges, especially when they emphasize freedom from patent limitations and are transparent in their promises and approach to the legal issue. However, again, because of the limited network effects, technology non-neutrality, and incentives to contribute to collective patent defense, peace provisions are limited in substantial ways. If anything, these provisions discourage proprietary communities from using OIC technologies for fear that they will forgo any value to their patents without significant benefits. The provisions also lack some transparency in that they do not provide a clear mechanism for identifying the patents that are specifically subject to the "peace" protection.

In terms of longevity, patent peace provisions last for the full patent term. However, no patent peace provision has ever been tested in court, so like other approaches, it remains to be seen how robust they are. One can imagine some challenges to the validity of such an agreement, especially for later-acquired patents or patents that have been sold off to third parties who then claim there is no privity with the original licensee.

\section{Patent Protection Groups: The Open Invention Network Model}

Patent protection groups are consortia or organizations that gather patents in order to pool their resources for a single purpose. One version of this is a patent pool, which can be an effective mechanism for organizing intellectual property licenses for technical standards ${ }^{155}$ and as a means of aggregating enforcement. The Open Invention Network ("OIN") has taken this approach to patent defense ${ }^{156}$ for the Linux operating system. ${ }^{157}$ Because the organization and approach can vary from patent protection group to patent protection group, we use OIN as an example of a particularly open and thoughtful version of the "pool" approach to OIC patent defense.

155. Peter Judge, IEEE to Set Up Patent Pools to Simplify Standards Adoption, PC WORLD (Dec. 8, 2008, 3:10 AM), http:// http://www.pcworld.com/article/155111/ieee patent_pools.html.

156. License Agreement, OPEN INVENTION NETWORK, http:// www.openinventionnetwork.com/pat_license.php (last visited Dec. 22, 2012).

157. We refer to "Linux" as an operating system for readability purposes, but we acknowledge that this is shorthand. See Richard Stallman, Linux and the GNU System, GNU OPERATING SYS., http://www.gnu.org/gnu/linux-and-gnu.html (last updated Oct. 25, 2012) (explaining the difference between the GNU operating system and the Linux kernel, and the combination of the two as a "GNU/Linux" system). 
As described on its website, OIN acquires

[I]mportant patents [to make them] openly shared in a collaborative environment. [OIN p]atents are available royalty-free to any company, institution or individual that agrees not to assert its patents against the Linux System. This enables companies to make significant corporate and capital expenditure investments in Linux - helping to fuel economic growth. $^{158}$

If Linux is threatened by a patent lawsuit, OIN stands ready to assert the patents in its pool to neutralize or diminish the threat. OIN has received fiscal or intellectual property donations from IBM, Novell, Philips, Red Hat, and Sony. ${ }^{159}$

In terms of costs and benefits, OIN concentrates its costs internally and among its fiscal and intellectual property benefactors. It distributes the benefits of its defensive portfolio to anyone who takes a license. And because OIN is committed to protecting Linux from patent threats, ${ }^{160}$ the defensive benefits of its patent pool are, at least theoretically, distributed further to anyone who uses Linux or innovates on top of it. However, OIN's centralized, hub-and-spoke model, in which the OIN hub engages in reciprocal licensing with many licensees using Linux, trades a strong, centralized ability to enforce patents in defense of one important product (Linux), for a more general distribution of benefits. So, for example, OIN provides few direct benefits to other OICs, including the Apache web server, Android, or FreeBSD, as well as the many applications that run on Linux. This leaves other OICs vulnerable to patent attacks even if they use Linux. For this reason, OIN's benefits are also limited in their network effects by the lack of technology neutrality and interoperability. ${ }^{161}$

The OIN model adopts many of the principles and mechanisms of OICs. For example, OIN creates transparency by openly providing a list of all the patents it owns, a copy of its standard license to its pa-

158. About OIN, supra note 130; see also Nick Wingfield, Group of Microsoft Rivals Nears Patent Deal in Bid to Protect Linux, WAll St. J., Sept. 8, 2009, at B1, available at http://online.wsj.com/article/SB125236988735891147.html.

159. Robin Cover, Open Invention Network Formed to Promote Linux and Spur Innovation Globally Through Access to Key Patents, XML Cover PAGES (Nov. 10, 2005), http://xml.coverpages.org/OIN-Announce.html.

160. See Frequently Asked Questions, OPEN INVENTION NETWORK, http://www.openinventionnetwork.com/about_faq.php (last visited Dec. 22, 2012).

161. Its costs are also somewhat obfuscated but seem concentrated among the firms that support it. While this may be sufficient to meet the cost-benefit ratio required for Linux as an OIC, it does not appear to extend to other OICs. 
tent portfolio, ${ }^{162}$ and a list of its licensees. ${ }^{163}$ The license is available to any entity that chooses to agree to its terms (which, importantly, include a license back to OIN of any patents that "read on" Linux), and is thus non-discriminatory. ${ }^{164}$ By defending Linux - the kernel of a common FOSS operating system and thus a central component of many FOSS production models - OIN supports the OIC norms of freedom and openness, ${ }^{165}$ including freedom to operate and innovate, access to knowledge, and non-discrimination.

On the issue of reliability, OIN's patent license seems to create longevity over the term of each patent committed, and seems to be at least as robust as other OIC licenses by remaining in place unless and until the licensee asserts patents against Linux. However, the reliability of models that depend on a centralized organization is less clear. The strength gained by centralizing costs and administration into one organization with the ability to act on behalf of the community requires both organizational longevity and a robust commitment to its stated defensive positions. Not unlike Google's pledge "Don't be evil," ${ }^{166}$ OIN has promised to be good, and to defend Linux according to the community's values. However, it is unclear if this is a legally binding commitment and if mechanisms for transparency or accountability exist to ensure or enforce it. Thus the OIN model relies heavily on trust and the value of its brand. However, there is no legal guarantee that OIN will continue to be a good actor. It could potentially sell off its patents to an offensive actor in the future that could target nonLinux OICs. This seems unlikely for OIN specifically, ${ }^{167}$ but other centralized pools may have less robust ties to the OIC community. More quotidian organizational issues - such as lack of funding or lack of leadership - can also arise, leaving stranded the community relying on a troubled patent protection group. This is a risk exacerbated by the relatively concentrated costs that arise if OICs shift to new technologies, standards, or platforms beyond those previously defended, i.e., if users move from Linux to FreeBSD. The costs of reconsti-

\footnotetext{
162. Currently Owned Patents, OPEN INVENTION NETWORK, http:// www.openinventionnetwork.com/pat_owned.php (last visited Dec. 22, 2012).

163. OIN Community of Licensees, OPEN INVENTION NETWORK, http:// www.openinventionnetwork.com/licensees.php (last visited Dec. 22, 2012).

164. See About OIN, supra note 130; License Agreement, supra note 156.

165. However, it is worth noting that because of its focus and centralization, OIN's transparency with regard to its actual enforcement strategies and actions is much more limited in relation to its openness in disclosing all patents, licensees, etc.

166. Code of Conduct, GOOGLE INVESTOR REL., http://investor.google.com/ corporate/code-of-conduct.html (last visited Dec. 22, 2012).

167. At the same time, whether OIN is fully trustworthy is the subject of some controversy in the FOSS community. See Dana Blankenhorn, Mueller Calls OIN a Scam, ZDNET (June 2, 2010, 5:26 PM), http://www.zdnet.com/blog/open-source/mueller-calls-oin-ascam/6613. Regardless of OIN's actual trustworthiness, any organization that must rely on trust in this way may generate similar controversy.
} 
tuting a defensive pool or organization on a technology-by-technology basis could be substantial and prohibitive.

\section{Synthesizing a Defensive Patent Strategy for OICs}

Each of the above strategies has some merit, though each has important limitations in its reach and effect. We recognize that some more limited solutions to OIC patent threats are intended to solve specific problems, and that each makes tradeoffs that may maximize the benefits demanded by these specific situations. Yet we think it is possible to develop a complementary approach that is more broadly applicable and that has the capacity to spread the benefits of defensive patenting across OICs. Drawing on our analysis of defensive patenting, OIC literature and practice, and the reach and limitations of the existing approaches we have discussed, we synthesize a framework with which to evaluate OIC patent defense strategies and to develop a more generalized approach. The framework addresses each of the barriers to defensive patenting we identified in Part II, and encompasses the four principles we distilled in Part III.A. Synthesizing these analyses shows that, to be most effective within the OIC context, a defensive patent strategy should maximize the following characteristics:

1. Distribution of Costs and Benefits

- Distribute Costs of Defensive Patent Acquisition

- Distribute Benefits of Defensive Protection

2. Respect for Relevant Cultural and Political Values

- Freedom to Operate and Freedom to Innovate

- Openness: Access to Knowledge

- Openness: Transparent and Non-Discriminatory Legal Terms and Enforcement Conditions

- Interoperability and Technology Neutrality

3. Reliability

- Longevity

- Robustness

With this framework in hand, we now turn to describing and evaluating our proposed Defensive Patent License strategy.

\section{The Defensive Patent License: A NeW StRAtegy For AdDREssing PATENT THREATs to OICs}

Each of the above approaches goes some distance in addressing patent threats for OICs, but each has limitations in its reach and effect. Therefore, working from our framework, we propose a new model for 
addressing OIC patent threats that is designed to maximize important benefits of existing models and address some of their limitations. Specifically, we model a distributed cross-licensing system anchored by an OIC-style standardized open patent license - the Defensive Patent License, or DPL. The DPL blends the general strategy of defensive patenting with the OIC values of openness and freedom, using a FOSS-inspired, decentralized and standardized intellectual property license to distribute costs and benefits, and to provide an interoperable, technologically neutral, reliable, and legally binding commitment to defense.

The DPL draws upon and reflects three basic principles, articulated for us by Brewster Kahle, founder of the Internet Archive, during our initial conversations with OICs about this idea.

The DPL is a license that reflects a public commitment to defense, so our patents are forever defensive.

Any organization may freely use these licensed patents while also being publicly committed to defense.

An organization that commits a breach of this license is ceasing its commitment to defense.

Overall, we believe that this approach could significantly lower the barriers and maximize the benefits of defensive patenting for OICs. In this Part, we describe the DPL and explain how it can help OICs protect themselves against patent threats.

\section{A. The DPL Model}

The DPL is a standardized open patent license designed to encourage the creation of a broad, decentralized network of OICs that both patent their innovations with a commitment to defensive purposes and license them on a royalty-free basis to any others who will do the same ${ }^{168}$ In doing so, the goal is to build up a collective network of patents that has the same deterrent power as a large proprietary defensive "portfolio" - but a portfolio that has its costs and benefits distributed across the users of the DPL, and that does not require separate centralized management. ${ }^{169}$ As such, we harness the network effects of OIC distributed cost and benefit structures, the commitment to OIC

168. For illustrative purposes, we provide a model version of the DPL in the Appendix to this Article.

169. We do suggest a centralized information management system for tracking DPL transactions but not for acquisition or enforcement, which constitute the largest costs of centralized defensive patenting consortia. 
values, and the reliability of other standard distributed OIC licenses, such as the GPL or Creative Commons' copyleft licenses, and apply them in the patent context.

The DPL operates by creating a set of viral, bilateral obligations focused on preventing offensive patent litigation and promoting freedom to operate and innovate. Specifically, the DPL provides every DPL user a perpetual, worldwide, royalty-free license to every other DPL user's entire current and future patent portfolio, ${ }^{170}$ subject to the following four conditions:

1. Every DPL user (licensor or licensee) will forgo any offensive patent infringement actions against any other DPL user;

2. Subject to Condition 4, every DPL user will offer her entire current and future patent portfolio under the DPL $;{ }^{171}$

3. Every DPL user will bind any successor-ininterest to any part of her patent portfolio to her obligations under the DPL ${ }^{172}$ and

4. If a DPL user wishes to stop offering her patents under the DPL, she may do so, but only with six months' notice to existing DPL users and future parties. She must continue to grant, and may not revoke, any licenses that are in place before the end of the notice period. ${ }^{173}$ Once she stops offering the DPL,

170. As defined, a patent portfolio includes every issued patent as well as any continuations, divisionals, applications, or provisionals. In other words, any filing with any patent office in the world that lays claim to a patent right of any kind is subject to the DPL. For users without any patents, they must simply commit to putting any patent rights they do acquire in the future under the DPL.

171. Much like Creative Commons, we have also considered the possibility of a suite of DPLs which could offer variations, both in terms of the level of portfolio commitment (for example, the whole portfolio versus a defined portion) as well as the strength of the licensee's viral obligation (for example, only a promise not to sue versus a promise to make all licensees agree to the same terms). While we see the merit to these variations, we will describe just the basic license in this Section and then discuss the pros and cons of the variations below.

172. There is one exception to this obligation: due to the common practice of having employees automatically assign patent rights in their inventions to their employers, patents that are subject to such agreements are exempt from the obligation to be licensed under the DPL unless the employer assignee is already a DPL participant. Otherwise, the inventor would breach her personal licenses every time the automatic assignment took place. This situation can also be addressed via the "inventor scope limitation" discussed below.

173. After this period, previously issued licenses remain in effect, but there is no obligation to issue licenses to new parties or on newly filed patent rights. Six months gives DPL 
other DPL users are free to revoke their licenses to her at will, but the DPLs she granted previously remain in effect.

All DPLs are irrevocable for the full term of the relevant patents, except if one or more of the above conditions are not met or if a DPL user provides six months' notice under Condition 4. Thus, if a licensee files an offensive patent infringement action ${ }^{174}$ against any other DPL user or leaves the network, then any other DPL user may then revoke the offender's DPL to his patents at any time and, at his option, pursue royalties or enforcement actions against her. ${ }^{175}$ Importantly, these obligations and conditions apply only with regard to any others who use the DPL. Any DPL user may independently pursue royalties or enforcement actions against any non-DPL user at any time.

To create administrative transparency and enhance enforceability, we envision that certain information about the network of DPL users would be available via a centralized website with a backend tracking database. All DPL users - along with publicly available information about their patent portfolios - would be listed on the site, along with contact information for where to request a license, and a mailing list for new information regarding patents under the DPL.

Thus, the mechanics of joining the DPL network would proceed as follows:

1. An inventor decides to begin offering her patents under the DPL;

2. She makes this publicly known (likely via her own website) and registers with the DPL tracking website;

users who are actively using the departing user's patents an opportunity to plan ahead, and helps prevent unfair surprise and gamesmanship on the part of DPL licensors.

174. Offensive patent infringement actions are defined as actions that are not filed in direct response to a previously filed patent infringement suit involving the same parties.

175. A plausible question to ask is, why not require all DPL users to sue any DPL violator so as to maximize the deterrent effect of the DPL network? We chose to keep the decision to sue voluntary for several reasons. First, patent litigation strategy is very complex and almost impossible to mandate via license agreement. Moreover, questions of cost would arise as to who would pay for the litigation. Therefore, rather than requiring litigation, we designed the DPL to align the interests of the users sufficiently so that there would be incentives to either step in and protect other users from patent threats, or possibly come to individual agreements allowing other users to enforce DPL patents for the patent owner, thereby having the threatened user absorb the costs. Moreover, we believe the mere threat of patent enforcement by numerous DPL users, for example through cease-and-desist letters, could be sufficient to deter outsiders from attacking any member of the network. 
3. Once registered, the website provides the inventor with a blanket DPL licensing form that she agrees will bind her in relation to anyone who accepts the license;

4. She then receives access to the pages for every other DPL user with an option to accept any or all of the DPLs for their portfolios. One can also imagine an option to accept all known DPLs in a single click. The website then distributes an acknowledgment of all license offers and acceptances to the participating parties and records them in its internal database. The licenses take effect immediately.

5. As new patents issue or new applications are published for each registered DPL user, they are added to the website, either automatically or by the DPL user herself. Each DPL user may then take additional licenses to newly issued patents either manually or automatically via the DPL website.

6. If the DPL user chooses to stop offering her patents under the DPL, she registers her six-month Discontinuation Notice at the website, which alerts all DPL users. Six months later, the DPL user's page is updated appropriately but all information related to the user and her portfolio remain preserved. Other DPL users are then given the option to revoke any licenses for the leaving user as of the Departure Date.

The figure below captures this sequence of events. The DPL thus provides incentives for innovators to legally commit themselves to defensive use of patents, rewarding participation with the benefits of unfettered access to the patents of other DPL users and freedom to operate with respect to DPL technologies. As the number of DPL users grows, they develop into an extensive cross-license network, with positive network effects eventually arising, increasing the benefit of joining and causing the network to grow more rapidly. The DPL provides disincentives to leave the network, as those leaving may potentially lose their licenses while those who remain keep theirs, even those licenses from the leaving party. In this way, patents subject to the DPL remain reliably defensive for all DPL users who remain in the network. For those outside the network, all DPL-licensed patents are still active threats; DPL users may seek licenses or enforcement against outsiders on any terms they wish. 


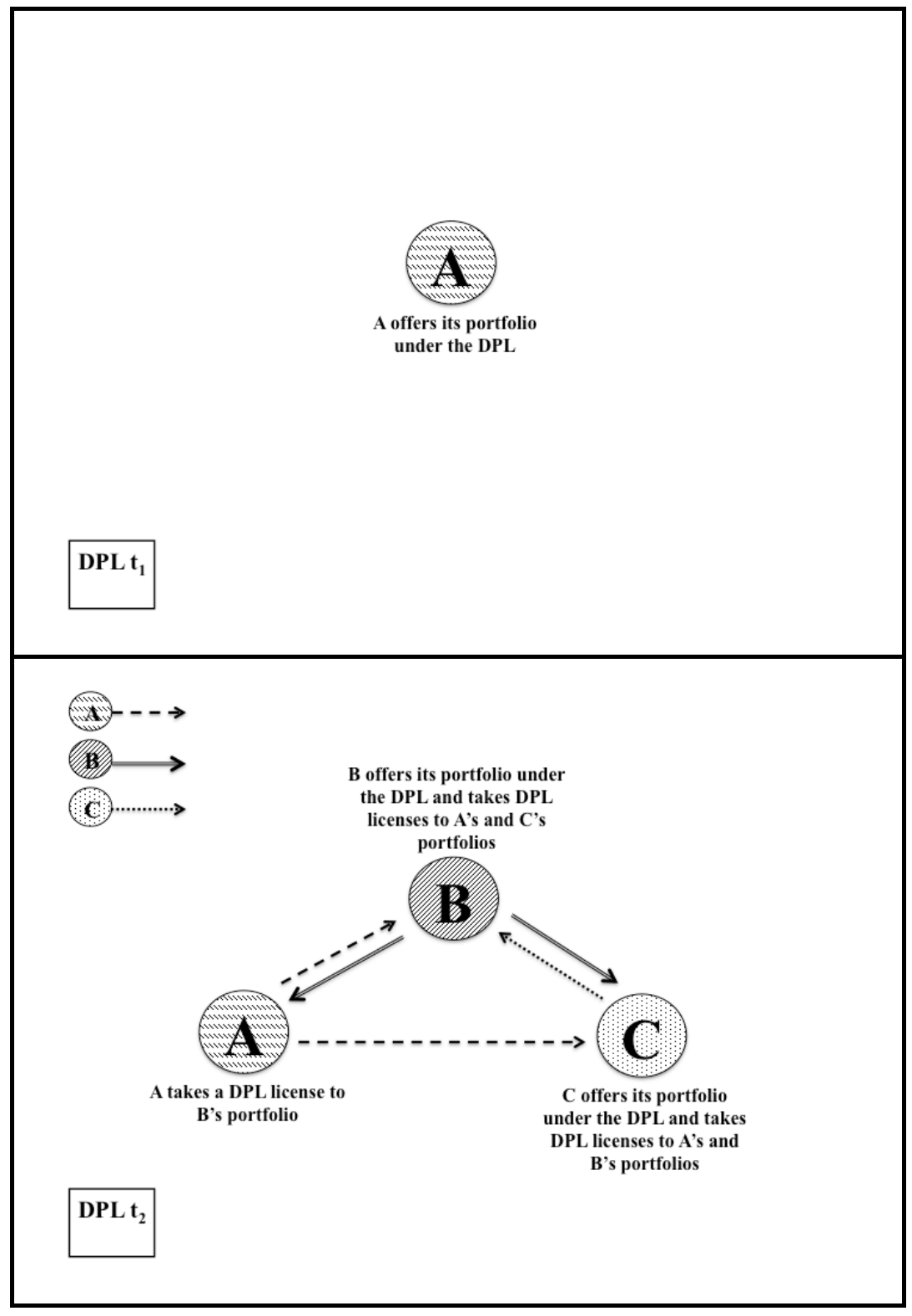

Figure 1: Example sequence of DPL events 


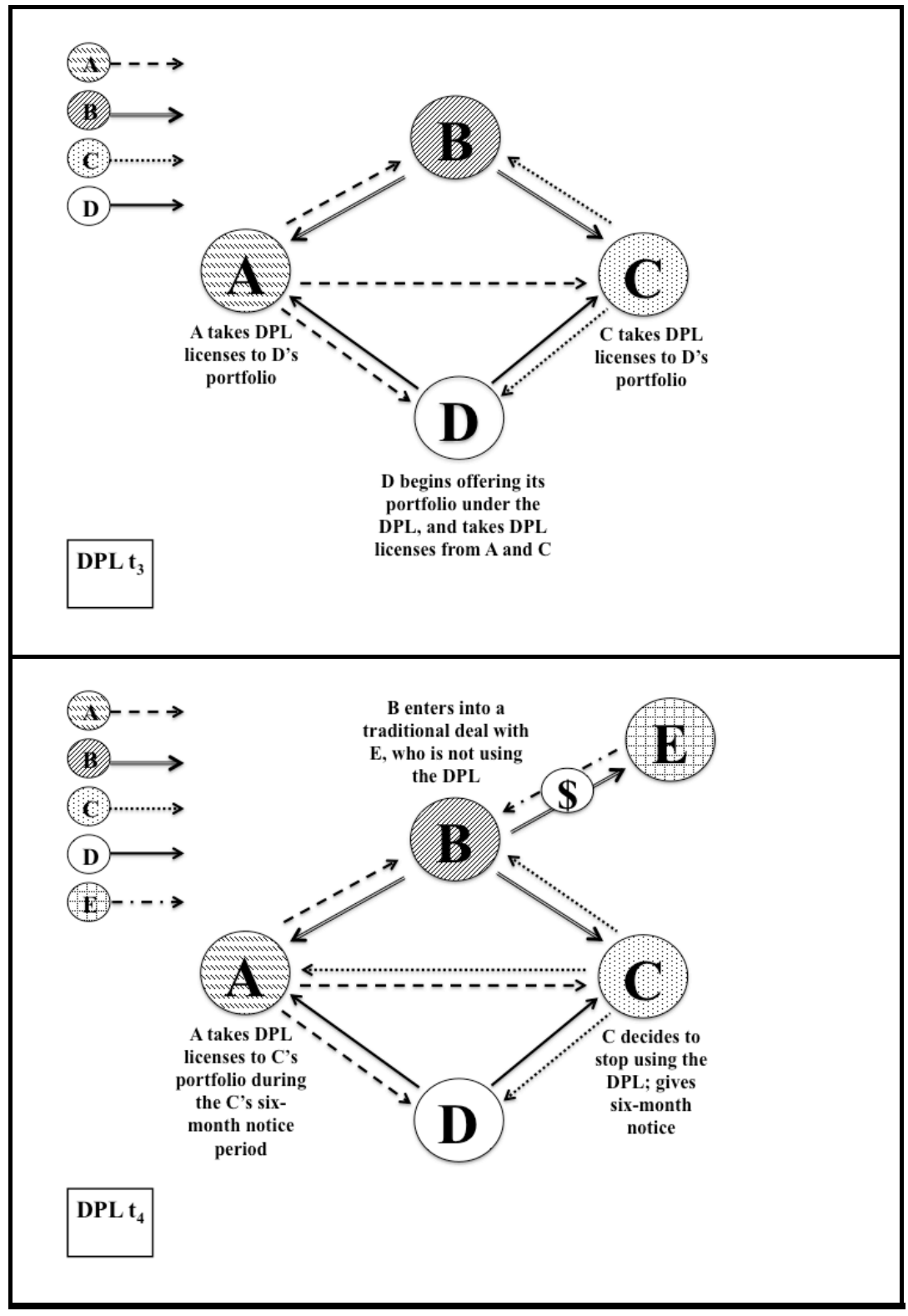

Figure 1: Example sequence of DPL events (continued) 


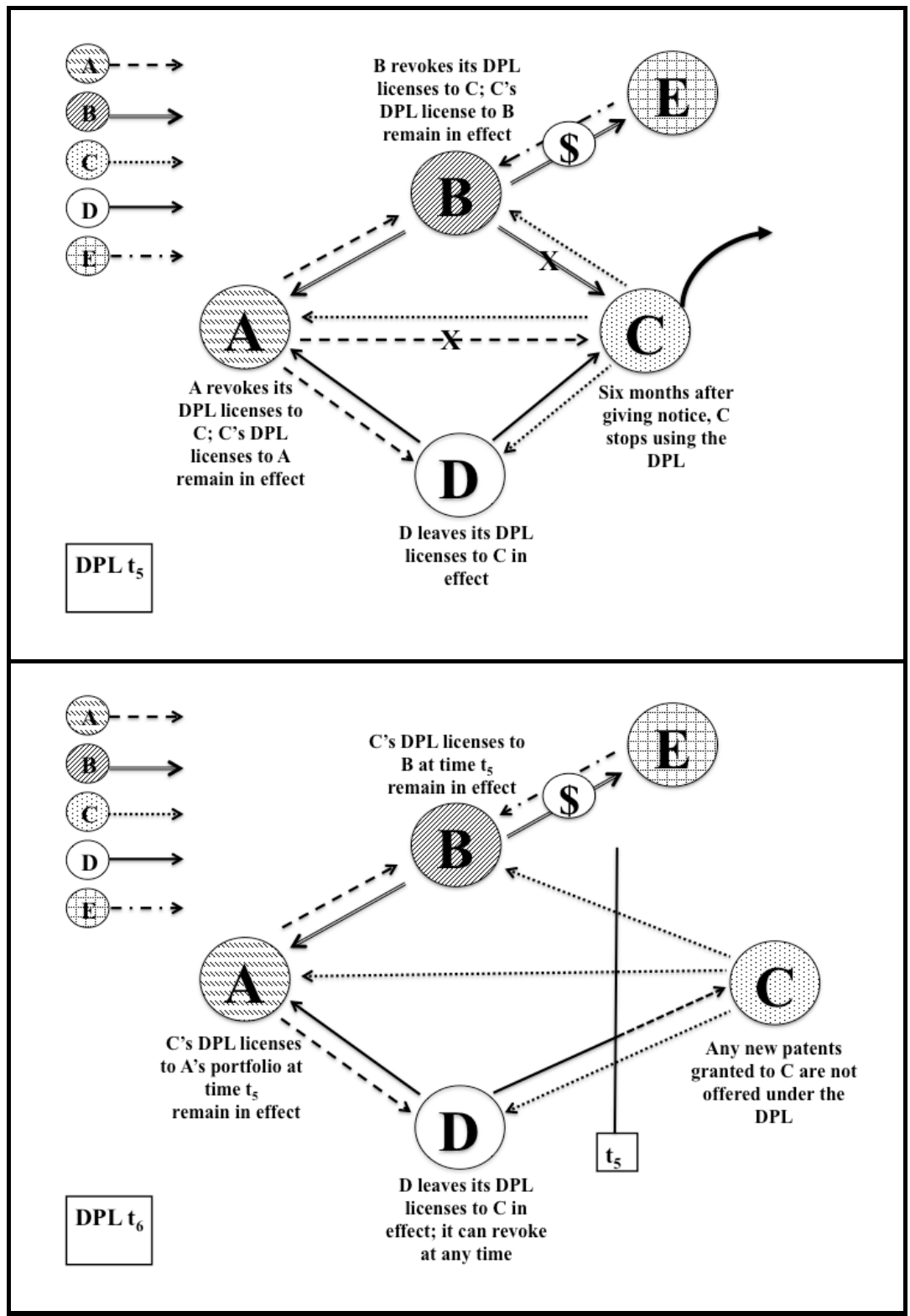

Figure 1: Example sequence of DPL events (continued) 


\section{B. Analyzing the DPL Under the OIC Patent Defense Framework}

\section{Distribution of Costs and Benefits}

We begin by evaluating the DPL under the first prong of our framework, which suggests that distributing the costs and benefits of patenting is likely to be an important factor in any defensive patent strategy for OICs. By leveraging the distributed open license model common to many OICs, the DPL tackles the problem of concentrated licensing and information costs and benefits. Because patent licenses are required to be equally and freely available to any DPL user, the benefits of each additional patent licensed under the DPL can be distributed equally and easily among the licensees. Through the same mechanism, the costs of patenting are also distributed, albeit not quite as equally. Much like the code production in FOSS projects is distributed, with some coders contributing proportionally more than others, but with any coder able to participate as her resources allow, so would innovation and patent prosecution be distributed in the DPL network.

By actively distributing costs and benefits in this way, the DPL increases access to patented technology, expanding the supply of tools for innovation. For example, if a member of an OIC wishes to find a particular technology to use and wants to make sure it comes with the freedoms that OICs support, he can search the DPL website for the appropriate patents and immediately receive licenses to them under the DPL. And much like other open licenses and formalized intellectual property pooling efforts, the DPL facilitates earlier and more widespread use of patented technology via non-discriminatory and royalty-free licensing and more rapid advancement of technology by clearing blocking positions and permitting more firms to improve on existing patented inventions. By encouraging a global network of patents licensed under the DPL, the quality of DPL-licensed products will improve more rapidly than if DPL users continued to be limited in terms of the patented technologies they could access. This is particularly true for firms with limited resources.

With regard to enforcement, our model does not include a centralized "brain" to coordinate enforcement actions, which makes it far less costly to administer and, we think, more reliable over time than a centralized model requiring staff and substantial ongoing resources. While the lack of a centralized brain also means that there is no centralized responsibility for enforcement, DPL users who share similar OIC values or who wish to come to the aid of other users who are under attack can either file protective lawsuits directly or offer to pay the costs of suit in return for initiating litigation. ${ }^{176}$ This model therefore

176. DPL users would likely not be able to authorize other users to file suit on their behalf. See Ortho Pharm. Corp. v. Genetics Inst., Inc., 52 F.3d 1026, 1034 (Fed. Cir. 1995) 
lacks a guarantee that enforcement efforts will occur, but also allows maximum flexibility in how each DPL user chooses to enforce their patents in specific situations. While the specific circumstances of each suit are too difficult to anticipate, we believe there will be enough common interest and common ground for defensive efforts to occur, and for the network to represent a credible deterrent against many offensive patent threats.

\section{A. Distributing Costs}

By allowing OICs to easily cross-license each other's patents, the DPL reduces the overall cost of patenting. This is not to say that all firms are likely to contribute equally: firms with limited resources may, at least at first, mostly benefit from access to others' patents. On the other hand, firms that already patent for other reasons, such as to attract venture capital or in order to license or enforce against nonDPL parties, would automatically contribute their patents to the DPL at no additional cost. So long as the overall network contains sufficient patents, the benefits of gaining licenses are likely to encourage additional users to begin using the DPL; as users gain patents, the network's collective portfolio will grow accordingly.

Moreover, we anticipate that, with a binding commitment to use the DPL, some OICs will choose to patent innovations they otherwise might have dedicated to the public domain in order to strengthen the defensive power of the DPL network. ${ }^{177}$ We think this is particularly promising among OICs with strong user innovation communities. And this appears to be a broader trend; according to Baldwin and von Hippel, user innovation in OICs is growing. ${ }^{178}$ Yet very few of these users patent their innovations. If there were a robust patent defense strategy that benefited from such patents, such as the DPL, these innovators might be convinced to patent their contributions and thus strengthen the network even more. This would also give them recognition for

("[A] right to sue clause cannot negate the requirement that, for co-plaintiff standing, a licensee must have beneficial ownership of some of the patentee's proprietary rights.").

177. We also hope to encourage pro bono patent prosecution for firms that commit to the DPL as an additional way of lowering the barriers to building the network. For example, the USPTO has recently approved a pilot program for legal clinics at U.S. law schools to assist in patent prosecution for parties who could not otherwise afford legal representation before the USPTO. In addition, the recent America Invents Act includes a provision allowing large fee discounts (up to 75\%) for "micro entities." See Law School Clinic Certification Pilot, U.S. PAT. \& TRADEMARK OFF., http://www.uspto.gov/ip/boards/oed/practitioner/ agents/law_school_pilot.jsp (last visited Dec. 22, 2012); Leigh Martinson, The America Invents Act and the Individual Inventor, CNET NEWS (Sept. 17, 2011, 2:42 PM), http://news.cnet.com/8301-1001_3-20107792-92/the-america-invents-act-and-theindividual-inventor.

178. Carliss Y. Baldwin \& Eric von Hippel, Modeling a Paradigm Shift: From Producer Innovation to User and Open Collaborative Innovation (Harv. Bus. Sch. Working Knowledge, Paper No. 10-038, 2009), available at http://hbswk.hbs.edu/item/6325.html. 
their work more broadly, and even potentially improve their value in various employment markets.

Though the basic costs of patenting - filing fees and attorneys' fees - remain the same for each individual patent that a DPL user might pursue, ${ }^{179}$ we think the DPL would greatly reduce important transaction costs related to defensive patenting. First, it facilitates easy cross-licensing by eliminating the need for costly negotiations between DPL patent holders. Second, it lowers information costs by providing a consistent baseline license with predictable terms for every user. Third, by providing a centralized website with all relevant information and an easy means of accepting DPLs, it greatly limits the legal and search costs associated with assessing the validity of potential patent threats from DPL-licensed patents.

\section{B. Distributing Benefits}

As noted above, by making patents available, neutrally and openly, to anyone who also agrees to use the DPL, the DPL distributes the benefits of patenting across the entire DPL network. Importantly, this distribution occurs across myriad OICs - any OIC, regardless of sector, that chooses to use the DPL - instead of across only individual communities or technologies. Anyone in the network can make, use, or sell any technology licensed under the DPL, making it technology neutral, scalable (as each new user simply becomes part of the network and does not impose significant costs on any central organizing entity), and interoperable. Further, anyone in the network can rely on the defensiveness of each of the patents under the DPL with little to no cost. ${ }^{180}$ Defensiveness is distributed across the network by virtue of the fact that licenses are irrevocable unless a licensee asserts her patents offensively against another DPL user or leaves the network. ${ }^{181}$ This allows each DPL user access to a networked defensive patent portfolio potentially far greater than she would have been able to ac-

179. Note, however, that these costs might be reduced via pro bono patent prosecution and common patent fee funds for innovators who commit to putting any patents they acquired under the DPL.

180. Those familiar with open copyright licenses such as Creative Commons and the GPL will notice that the scope of the DPL is much broader. Rather than merely applying to future derivatives of the originally-licensed code, it applies to all licensee patents - past, present, and future - unless and until the licensee leaves the network. This is intentional, as patents are not congruent with copyright, and have much more damaging potential, precisely because they apply beyond derivatives, to anything the patent reads on. They claim the entire space. So in order to achieve defensiveness, the license has to address the scope of the threat. Moreover, the notion of a "derivative" in copyright licenses rests on the statutory definition which patent law lacks. See supra Part III.A.2.A.i.

181. The GPLv3 uses a similar mechanism in its "patent peace provision," which terminates the copyright license, along with any patent licenses, in the event that a user initiates a patent claim against a contributor to the licensed program. See The GNU General Public License v3.0, supra note 22. 
quire alone, and creates a potential arsenal that should greatly deter offensive users of patents. ${ }^{182}$ As the network grows, the defensive benefits grow accordingly and are distributed across the network. ${ }^{183}$

Thus, as the DPL gains adoption, the number of DPL users will grow and the network effects of the license will increase the benefits to each licensee. This in turn will increase freedom to operate and the overall commitment to defense for those in the network, while simultaneously offering increasing incentives to those outside the network to join. It also offers the benefits of establishing "gold standard" prior art that prevents non-OICs from patenting OIC technology. The potential to assert OIC patents against non-OIC entities for damages, royalties, and injunctions, is an incentive to join the network, since non-OICs are not covered by the definition of defensiveness. Such assertions could also occur as a matter of community defense when a non-DPL entity threatens a DPL user without any patents of its own.

As compared to some of the other defensive strategies we have considered here, ${ }^{184}$ the DPL can provide many of the same benefits, but distributed more broadly, across any technology sector with a DPL uptake. There is no need to create an entity to manage a patent pool, and no need to evaluate which patents should be put under a defensive pledge. DPL users can still choose to offer pledges or agree to patent peace provisions outside of the DPL network, but may choose to forgo these strategies as the network grows. In addition, because OICs will be patenting defensively instead of publishing defensively, their innovations will become more effective prior art within the USPTO and courtrooms, helping to prevent subsequent patenting of anything they use.

\section{Possible Challenges to Generating Network Effects}

For the DPL to most effectively distribute both the costs and benefits of defensive patenting across OICs, a sufficiently sized network of DPL users must develop. Therefore, if barriers to adoption are too high, or incentives are too low, then the DPL is less likely to generate the positive network effects that would make it most useful to OICs.

182. Note that DPL users are not required to leap to the defense of the threatened user. This decision can be criticized as creating too weak a disincentive for bad behavior; we think, however, that the possibility of suit would be a substantial deterrent to bad behavior for any DPL user that has taken a license to DPL's technologies. In addition, making the approach optional reduces the barrier to entry to using the DPL. We respond to these concerns in more detail below.

183. The fact that each DPL user offers up its entire portfolio maximizes the benefits of the license. We recognize that requiring the entire portfolio could represent a substantial barrier for some companies and we discuss alternatives below. However, the beneficial network effects of the DPL are likely to grow much more quickly with an all-in commitment.

184. See supra Part III.B. 
We address two important concerns about incentives and barriers to adoption here: concerns about barriers created by the DPL's "all-in" requirement, and concerns about sufficient capital investment in OICs.

\section{i. Balancing Barriers Created by the All-In Requirement}

A notable feature of our model DPL is its all-in requirement that firms offer all of their patents under the DPL rather than picking and choosing individual patents from their portfolio. This could represent a barrier to entry for both traditional proprietary firms and OIC firms. In our conversations with representatives of both types of companies, individuals suggested that they might well be willing to put some of their patents under the DPL, but asking them to put all of their patents under the DPL would be too large a commitment. In particular, where companies had split business models for different products, the idea of having to license one's entire portfolio presented a challenge: for example, proprietary versus OIC, or where their core businesses were ultracompetitive (and thus less amenable to broad licensing), while more peripheral parts of the business were less competitive.

At the same time, a variety of entities are concerned about gamesmanship - and the all-in model limits this concern substantially. Allowing DPL users to make only partial commitments would open up extensive opportunities for gamesmanship by offering only select (perhaps "junk") patents, and would increase the information costs of assessing which patents of a firm are valuable, which are necessary, and which are potential threats. If all patents are licensed, by contrast, there are far fewer determinations to be made; one simply takes a license to all desired patents under the DPL for free. Therefore, gamesmanship concerns must be weighed against worries over closing off possible future business models or limiting a firm's ability to split existing models. In the aggregate, we think that the all-in model creates the most benefit in this balance, and that the cost for many OIC firms is relatively low.

Nonetheless, we contemplate three possible variants on the scope of the DPL that would allow for partial portfolio commitments while limiting gamesmanship: (1) where the DPL user commits all patents that are defined under a specific independent technical standard, (2) where the DPL user commits all patents that are invented by specific inventors, and (3) where the DPL user commits all patents that cover a technology as defined by a neutral third party, such as a regulatory agency (for example, the Federal Communications Commission). In these instances, the reciprocal scope of the licensees' DPLs would only cover the technologies that substantially embodied these standards, the work of these inventors, or the technologies that were the 
subject of these regulations, respectively. Using such neutral, objective, and verifiable categories to define the scope of the DPL commitment would limit the amount of gamesmanship one could engage in and force the patent holders and licensees to share the information cost of determining which patents fall under the license. So, for example, a company such as Facebook could offer DPLs on all of its patents that list Mark Zuckerberg as an inventor. This would limit the number of patents under the DPL, but it would also limit the scope of the reciprocal licenses to Facebook. Facebook would only receive reciprocal licenses to projects that substantially embody Zuckerberg's personal work. Projects he has not worked on could still potentially infringe. Thus, the incentives would be to add more inventors to the list of "By Inventor" DPL patents in order to provide more freedom to operate for more projects. And by leaving out patents by other inventors, it would signal to the community that those patents are more likely to be used offensively. It would also allow specific inventors to bargain in their recruitment or employment contracts to have patents they invent put under the DPL without forcing the company to put its entire portfolio under the license. Therefore, while our Model DPL is based on the all-in model, these other variants are also possible.

Another variant worth discussing is what David Hayes and Eric Schulman call the "non-sticky" option in their response to this Article. ${ }^{185}$ The Hayes and Schulman approach preserves the entire portfolio aspect of our all-in model while initially limiting exposure to future regrets from issuing irrevocable licenses. ${ }^{186}$ Under this option, the DPL licensor would publicly announce a specific time period (for example, between zero and sixty months) where their participation in the network would be "non-sticky" - meaning that it could give its six-month notice and then abandon any DPLs it undertook, revoke any DPLs it issued, and leave the network. However, if the announced time period elapses and the licensor is still part of the DPL network,

185. Hayes and Schulman have discussed their thoughts on this option, among other considerations and responses to the DPL. David L. Hayes \& C. Eric Schulman, An Early Response to a Recent Proposal for a Defensive Patent License (DPL) 6 (2012) (unpublished working paper), available at http://papers.ssrn.com/sol3/papers.cfm?abstract_id=2054314. We sincerely appreciate their time and thought in their work on this topic.

186. Hayes and Schulman have also provided a number of additional suggestions and useful technical edits, many of which we have adopted in the Model Defensive Patent License provided in the Appendix to this Article. There are two we have not adopted, but would like to call attention to here. First, Hayes and Schulman note that companies with substantial patent portfolios may be especially worried about competitors creating cloned products or services under the DPL, and suggest carving out cloning and foundry products. See id. at 8,11 . Second, they identify the conundrum that existing exclusive licenses might pose for potential DPL users, and suggest carving out all patents exclusively licensed prior to a user joining the DPL, provided that these licenses were entered into in good faith and not to circumvent the DPL's requirements. See id. at 8 . We worry that these good faith requirements would be difficult to enforce effectively, but we do agree that exclusive licenses pose an issue for prospective DPL users. 
its licenses would become "sticky," meaning that they become irrevocable even if the licensor left the network, except under the offensive conditions outlined above in Part III.A. ${ }^{187}$

This sticky/non-sticky option strikes us as a smart way to encourage what Hayes and Schulman call "Substantial Portfolio Companies" to participate in the DPL network. ${ }^{188}$ For example, a company such as Google might wish to experiment with DPL participation before committing its entire portfolio permanently. In such a scenario, it would offer DPLs to all of its patents but designate the license as "non-sticky" for, say, twenty-four months. This would be part of the license and thus transparent to any licensee. If Google finds participation to be positive, then after twenty-four months, all of its licenses become automatically sticky. However, if Google wishes to revoke its DPLs, it can do so as long as it notifies all licensees before the twenty-fourth month. Hayes and Schulman argue that this approach has multiple advantages. It provides SPCs with incentives to try the DPL, allowing them to "dip their toes" in the DPL pool and gain data and experience in order to make a much more realistic and practical assessment of the benefits and costs. ${ }^{189}$ Second, it allows each licensor to choose its own sticky deadline and thus customize the license to its particular business model and community norms. ${ }^{190}$ Third, it establishes "stickiness" as the ultimate default so that unless a licensor takes explicit actions to notify licensees, the obligations will become permanent. This not only encourages most licensors to follow the default, but also means that those who do revoke their licenses will stand out more and likely generate press and publicity for doing so, signaling clearly that they are no longer committed to defensiveness and putting the rest of their community on alert.

\section{ii. Concerns about Capital Investment}

During our presentation of this idea to members of various innovative communities, some participants have expressed concern that the DPL will be practically unavailable to some OIC firms pursuing venture capital because they have foregone the opportunity to assert their patents offensively against competitors or for licensing revenue, a feature that could undermine incentives for venture financing. First,

187. See id. at 6 .

188. See id. at 2 .

189. See id. at 7.

190. For OICs in particular, we expect there to be external (from talent prospects and competitors) and internal (from employees) pressure to minimize the non-sticky state. Certainly in terms of labor market dynamics, it would allow companies to distinguish themselves when they recruit engineers. On the other hand, we might also expect pressure from investors, business units within a multi-business company, board members, or others to maximize perceived flexibility, which could militate in favor of maximizing the non-sticky state. Accordingly, we see some risk to this option. 
it is important to recognize that the DPL may in fact not be for every firm. For firms with business models that heavily depend on offensive enforcement of patents for exclusion or licensing revenue, the DPL may not be a viable model. However, it is also true that the DPL does not "disarm" patents against all other entities; rather, it only promises that the DPL user will be defensive as to others who make the same commitment. Those who are not part of the DPL network can be sued for patent infringement or approached for licensing revenues by a firm using the DPL just as easily as by a firm that is not using the DPL. Moreover, in return for licensing its patents under the DPL, a firm gains royalty-free access to all patents held by other DPL users. Both of these significant benefits to the firm's bottom line would need to be weighed against any license revenue from DPL users that would be lost. More generally, the DPL is modeled specifically for OIC firms, for which the enforcement of intellectual property has rarely, if ever, been a primary pathway to profitability. Instead, OICs focus on other incentives for production and profit, using intellectual property to secure freedom and openness, as reflected by the DPL.

Based on our framework analysis, we think that maximizing the distribution of both costs and benefits is an essential component of a successful defensive patenting strategy for OICs. Therefore, our model attempts to maximize these possibilities while avoiding barriers to entry substantial enough to prevent the network from growing sufficiently to allow for effective distribution. Not only does this approach mirror and harness the distributed approach to production that OICs already employ, recreating the success of those models, but it also matches the normative cultural and political preferences of OICs much more closely than traditional patenting strategies.

\section{Respect for Relevant Cultural and Political Values}

The second framework criterion - reflecting OICs' cultural and political values - is essential to any patenting strategy aimed at helping them. As described more fully above, many OIC participants have strong political or philosophical concerns about software, Internet, and other abstract patents, and in some cases, about the patent system more generally. The strong exclusive rights offered by patents are seen to work directly against core community values of freedom and openness. ${ }^{191}$ Therefore, it is necessary for any patent strategy aimed at helping OICs to both respect and reflect these values. While the most

191. See, e.g., Red Hat Statement, supra note 128 ("Red Hat has consistently taken the position that software patents generally impede innovation in software development and that software patents are inconsistent with open source/free software."); Patent Reform is Not Enough, GNU OPERATING SYS., http://www.gnu.org/philosophy/patent-reform-is-notenough.html (last visited Dec. 22, 2012). 
direct approach might be to restrict patentable subject matter to areas that are less threatening to OICs, in light of Bilski v. Kappos, we think it is unlikely that there will be a successful attack on the appropriateness of software as patent subject matter any time soon. ${ }^{192}$ Therefore, as a practical matter, the DPL model turns to private ordering alternatives to diminish the perceived threat of software patents rather than waiting for legal reform on the issue. In this regard, both the software patent debate and the DPL as a method for addressing it mirror the debate over software copyright and the development of FOSS licensing. Originally, many programmers objected to the copyrightability of software, much like the current objections to the patentability of software. ${ }^{193}$ However, in light of continuing court decisions and legislation reinforcing software's copyrightability, the FOSS licensing schemes became more accepted in the community as a mechanism to mitigate harms. Given the Bilski decision and the current trends in patent legislation, we believe a case for a similar instrumental approach to software patents makes sense, and have designed the DPL to maximize the norms of freedom and openness, and to use the licensing methodology that is now accepted among OICs for copyright. ${ }^{194}$

In doing so, the DPL approaches patents in a manner that is more culturally and politically compatible with OICs than many patent pools, and certainly most individual defensive portfolios. ${ }^{195}$ More specifically, the DPL explicitly supports broad freedom to innovate, access to knowledge, and protection from legal constraint. All DPL users must give other DPL users full freedom to operate and innovate vis-à-vis their patents, and must offer their patents transparently, neutrally, and robustly. By making freedom and openness central requirements of the license, the DPL attempts to address the community's understandable lack of trust in defensive patenting by individual entities.

192. See supra notes 56-59 and accompanying text.

193. See Richard M. Stallman, Why Software Should Be Free, in Free Software, Free Society: SElected ESSAYS OF RichaRd M. Stallman 121, 122-28 (2004). Academics also expressed concerns about how copyright has been applied to software innovation. See Pamela Samuelson et al., A Manifesto Concerning the Legal Protection of Computer Programs, 94 COLUM. L. REV. 2308, 2347-56 (1994).

194. This is also somewhat similar to the trajectory of Creative Commons. After Lawrence Lessig's constitutional challenge to the Copyright Term Extension Act was rejected by the Supreme Court in Eldred v. Ashcroft, 537 U.S. 186 (2003), he invested his energy into Creative Commons and its private ordering system as an alternative way to support free culture. See Meera Nair, Eight Years after Eldred, FAIR DUTY (Jan. 14, 2011, 07:18 PM), http://fairduty.wordpress.com/2011/01/14/eight-years-after-eldred.

195. For example, because the DPL's defensiveness, openness, and freedom attributes are requirements of the license, questions of the patent holder's present or future motives are much less likely to arise. Whereas Red Hat must reassure the community of its commitment to defensiveness and general opposition to software patents, see supra note 128, the DPL enforces community norms as inherent terms of its license. 
Further, with sufficient uptake, we think the DPL can begin to address some perceived patent threats indirectly, thereby supporting community norms more broadly. For example, by patenting and then placing those patents under the DPL, users essentially engage in a robust form of defensive publishing. As with defensive publishing generally, this may reduce the number of overbroad or invalid patents granted by the USPTO. It is well-known that previously published or issued patents are often the first source of prior art that examiners turn to when considering the issues of novelty or non-obviousness in another application. To the extent the DPL reassures OICs or encourages to file for patents on their innovations, these filings will provide additional information to patent examiners when they attempt to determine the patentability of a new application. As noted above, while defensive publishing of source code is an important ongoing community effort, the information costs of translating this documentation into language that easily maps to the claims of a patent can be high, and the risk that an examiner might not see the overlap between FOSS publications and future patent applications is non-trivial. ${ }^{196}$ By filing for DPL-committed patents, OICs would create a more easily accessible record for patent examiners, and with it a stronger chance that problematic future patent applications could be effectively narrowed or rejected entirely, creating fewer opportunities for patent trolls or other opportunistic enforcement entities. ${ }^{197}$

Although the DPL does not offer a direct defense against patent trolls (because they are essentially immune to suit, no defensive patent can be effectively wielded against them), it can also address OICs' fears of their patents being turned against them by reducing the pool of available patents that can be used for aggressive litigation by trolls. Specifically, because each DPL is generally irrevocable and legally commits the licensor to bind any successor-in-interest to similar terms, any subsequent sale of a patent right to a troll would require the troll to respect the DPL commitments. Should a troll attempt to use the patent to sue a DPL user anyway, the seller would then be re-

196. As we describe supra Part III.B.1, defensive publication can sometimes still impose high search and information costs on examiners and patent defense lawyers because the publications are not easily linked to patent claims. Defensively filed patents, on the other hand, are all situated within the USPTO's database, classified by technology, and written in the language that patent examiners are most familiar with. Moreover, judges are far more likely to find them in prior art searches because of the semantic similarities. In that sense, defensive patenting has all the benefits of defensive publication in addition to enforceability against opposing parties in offensive patent suits, not just defense to claims of infringement.

197. The recent switch to a "first-to-file" system provides even further opportunity for FOSS patent applications to prevent proprietary firms from patenting in the areas in which OICs are innovating. See generally Christopher Arnold, The AIA and TTOS: How Technology Transfer Offices Can Best Handle the Changes in Patent Law Brought About by the America Invents Act, 41 J.L. \& EDUC. 417 (2012) (explaining the change from a first-toinvent to a first-to-file system). 
quired to enforce the troll's promise to respect the DPL commitment or would itself be in breach. Moreover, any DPL licensee of the patent would already be inoculated from the threat of infringement via the irrevocable license. This combination of DPL obligations and a reduction in potential targets should make DPL patents unattractive to trolls. Moreover, the potential to receive a DPL before patents are sold off in the future also provides an additional incentive for other firms to join the DPL network. ${ }^{198}$

It might be advisable to add an optional "Anti-Troll Assignment" provision to the DPL. This provision would explicitly state that if a DPL patent is ever acquired and asserted by a company that does not research, develop, or produce technology in the field of a patent's invention, then the original licensors' DPLs become revocable. DPL users could choose to sign up for this provision, or not. This could provide useful "belt-and-suspenders" safeguards against attracting trolls for those DPL users who are especially concerned about that possibility.

If OICs were to start patenting innovations without a clear legal commitment in place to support the community's norms of freedom and openness, they might be perceived to be violating those norms. The DPL, however, enforces the norms through its operation, and ensures that patents, much like GPL copyrights, cannot be used to limit any other DPL user's ability to make and use technology, or to engage in a commons-based production model. More broadly, in the political economy of intellectual property debates, having intellectual property assets helps get you both a seat at the table and a voice of greater legitimacy in conversations about intellectual property policy. At present, OICs have, for the most part, opted out of the patent system, giving them little voice in patent policy debates and putting them at risk of being seen as outsiders or adversaries to patent systems. If OICs were to start building a large collective portfolio under the DPL, however, they would likely be able to leverage this clear interest in intellectual property assets for greater credibility in policy venues by positioning themselves as intellectual property owners, albeit intellectual property owners who are driven by goals of openness, freedom, and collaboration, rather than financial or exclusionary goals.

198. This model is somewhat similar to various "defensive patent aggregator" business models that have sprung up recently. See, e.g., ALLIED SECURITY TRUST, http://www.alliedsecuritytrust.com (last visited Dec. 22, 2012); RPX RATIONAL PATENT, http://www.rpxcorp.com (last visited Dec. 22, 2012). However, the proposed model would be much more inclusive because there would be no cost to join. 


\section{Ensuring Reliability}

Our third framework criterion - reliability - is a main reason why we chose a licensing structure for our approach. Where defensive pledges may change with future decisions by the patent holder, the DPL's general irrevocability and successor obligations are intended to ensure that defensive patents remain defensive and available to any other DPL user. Therefore, any DPL licensee can assume that it will be safe from patent lawsuits asserting any DPL patent continuously over time - alleviating concerns that the licensee's freedom to operate could evaporate in the event that a licensor changes its strategic approach or is acquired. Further, because the license can be revoked if (and only if) a DPL user stops acting defensively against other DPL users, it supports a reliable commitment of defensiveness within the network of DPL users. Therefore, the license structure greatly alleviates OICs' strong concerns that entities that state they are engaging in defensive patenting - yet make no enforceable promises to remain defensive - will change their minds later. If an entity chooses to use the DPL, then the commitment to defensiveness becomes reliable.

Therefore, longevity and robustness are built into the DPL through the license structure and terms. Besides being largely irrevocable, all DPLs are perpetual and fully paid up, so they will last as long as the patent does and expire only at the end of the patent term. Second, in addition to "traveling with the patent" to a new entity if patents are sold, we believe that the DPL can be drafted to survive both bankruptcy and any antitrust complaints. Third, rather than relying on the branding and trust capital of a centralized organization, the DPL self-executes; if a licensee abandons defensiveness, any of its licensors may choose to enforce against it. And while each independent DPL entity makes an independent decision about whether to enforce, the DPL itself (rather than a centralized, non-transparent decision-maker) sets the terms for and definitions of offensive and defensive legal action, giving all parties clear enforcement conditions so they can adjust their behaviors and plan for risks accordingly.

As noted above, a major reliability challenge for any defensive model is gamesmanship. In this case, we attempt to balance the need to protect against gamesmanship with the benefits of low barriers to entry and low administrative costs. The first concern is junk patents: if requirements for using the DPL are not sufficiently robust, then there is a risk that an entity will simply offer patents that are not valuable, saving valuable patents for possible offensive use against other DPL users. ${ }^{199}$ Requiring all of a firm's patents to be offered under the DPL

199. Standard-setting organizations face similar gamesmanship problems. See Mark A. Lemley, Intellectual Property Rights and Standard-Setting Organizations, 90 CALIF. L. REV. 1889, 1912 (2002) (describing strategic withdrawal from standard-setting organiza- 
guards against this. To limit the barrier to entry that the DPL all-in model creates, as well as to maximize freedom, DPL users may stop using the DPL at any time. However, again, in order to limit gamesmanship, they must give six months' notice before leaving, and all existing licenses remain in place. In other words, a DPL user may always cease offering future patents under the DPL, but must honor existing commitments. Further, during the six-month notice period, other DPL users may take any licenses needed from the leaving party, allowing them to plan for change and preventing the leaving party from packing up and stranding existing users. Finally, while the leaving party must honor any DPL commitment existing at the time it leaves, other DPL members may choose to revoke their licenses to it. Similarly, by "traveling with the patent" into any subsidiaries, affiliates and the like, the DPL reduces the ability of firms to use shell companies to engage in gamesmanship.

Perhaps the most complex set of reliability concerns relate to efforts at gamesmanship that involve the use of multiple entities to avoid the all-in requirement, the resale of DPL patents, or bankruptcy. ${ }^{200}$ For example, entities motivated to attempt gamesmanship might try setting up shell corporations, transferring all of their offensive patents into those corporations, and then taking DPLs for their practicing entities, thereby gaining protection against OICs while allowing their shell corporations to sue them. While many versions of this scenario are possible with some difference in the details, all involve the use of multiple entities or patent transfers. For this reason, the DPL contains a broad successors-in-interest clause that allows DPL users to revoke any licenses of another DPL user if that user has economic or administrative control over a third party who files an offensive suit. While this cannot reach gamesmanship coordinated by truly independent actors, we believe that it is sufficient to prevent most forms of gamesmanship.

A related concern is that bankruptcy could upset the DPL equation by allowing a bankruptcy court to cancel DPLs on a patent that needed to be liquidated in order to satisfy creditors of the previous licensor. $^{201}$ This raises the specter of trolls or other entities buying up

tions); Bernhard Ganglmair \& Emanuele Tarantino, Patent Disclosure in Standard Setting 2-3 (NET Inst., Working Paper No. 11-15, 2011), available at http://ssrn.com/abstract=1957991 (describing firms' potential to opportunistically disclose patents to standard-setting organizations).

200. We are grateful to the many astute commentators from both academe and industry who have proposed various scenarios gamers could use to avoid the full set of DPL obligations. These observations have helped us immensely in balancing gamesmanship protections with other features in the DPL model.

201. See David R. Kuney, Restructuring Dilemmas for the High Technology Licensee: Will "Plain Meaning" Bring Order to the Chaotic Bankruptcy Law for Assumption and Assignment of Technology Licenses?, 44 GoNZ. L. REV. 123, 136 (2008) (explaining that bankruptcy laws codify this principle of free assignability and that "[t]he right to assign 
previously DPL-licensed patents and using them offensively against DPL users, diminishing the reliability of the DPL's promises. However, under $\S 365$ (c) of the Bankruptcy Code, a trustee cannot generally assume or assign a non-exclusive patent license without "consent" of other parties to the license. ${ }^{202}$ Moreover, $\S 365(\mathrm{n})$ allows any intellectual property licensee to retain its rights under the license for the duration of the license, even through bankruptcy. ${ }^{203}$ Thus, it seems that any promise by a DPL user not to sue other DPL users offensively can remain with the patent and be upheld in bankruptcy. ${ }^{204}$

Several commentators have also raised concerns that the DPL might draw antitrust scrutiny as a collusive practice. In other words, if viewed as a set of agreements to price certain patents at no cost and to require others to do the same, one could see questions of competition policy arising. However, the patent and patent pool antitrust literature clarify that such arrangements are rarely a problem as long as certain competitive safeguards are in place. Specifically, the Department of Justice has generally approved patent pools and similar arrangements as long as they provide, inter alia, the following competitive safeguards:

1. Limitation of the portfolio to technically essential patents which, by definition, are not competitive with each other.

2. Portfolio patents are clearly identified and can be licensed individually as well as in a package.

3. Issue of worldwide non-exclusive licenses.

4. Licensee liability for royalties conditioned on actual use of the patents.

valuable contract rights is often what makes a Chapter 11 reorganization feasible because it provides value to the estate and a raison d'etre for the bankruptcy filing"); Peter S. Menell, Bankruptcy Treatment of Intellectual Property Assets: An Economic Analysis, 22 BERKELEY TECH. L.J. 733, 751-52 (2007) (noting that the bankruptcy system supports the assignability and fungibility of assets, including intellectual property licenses); Jennifer Ying, Comment, The Plain Meaning of Section 365(c): The Tension Between Bankruptcy and Patent Law in Patent Licensing, 158 U. PA. L. REV. 1225, 1228 (2010) ("Bankruptcy law relies on the concept of freely assignable rights of property in order to facilitate the restructuring and reorganization of the debtor"). But see In re Gencor Indus., Inc., 298 B.R. 902, 913 (Bankr. M.D. Fla. 2003) (finding that the patent license in question was not an executory contract under the Bankruptcy Code and thus remained enforceable).

202. 11 U.S.C. $\S 365(\mathrm{c})(2006)$.

203. 11 U.S.C. $\$ 365(n)(1)-(3)(2006)$.

204. See In re Spansion Inc., No. 09-1069, 2011 WL 3268084, at*7-9 (D. Del. July 28, 2011) (upholding promise not to sue as a valid patent license under $\S 365(\mathrm{n})$ and thus enforceable even through bankruptcy). 
5. Freedom of licensees to develop and use alternative technologies.

6. Requirement that licensees grant back nonexclusive, non-discriminatory licenses to use patents that are essential to comply with the technology. ${ }^{205}$

Not only does the DPL have these safeguards in place, but it also allows more people to access the patents in the network because the price is zero for any license. Moreover, unless a pool has market power in a particular field, there is far less concern over anti-competitive outcomes. $^{206}$

Finally, a centralized model that relies on an ongoing entity which would need ongoing funding, staffing, and measures to ensure transparency to the community and to ensure that it is pursuing community goals - would raise separate reliability concerns. By using a FOSS-style, standardized cross-license as the organizing mechanism, the DPL model is intended to greatly lower administrative costs and eliminate the need for centralized decision-making, also limiting the need for ongoing trust in a centralized entity. While we envision a nonprofit running the centralized tracking website described above, there is no need for anyone to manage a costly centralized pool limiting the risk of resource constraints - and no need to rely on the judgment and values of one group or entity over time. Therefore, the DPL model is robustly defensive.

\section{CONCLUSION}

As OICs continue to increase their presence and influence across all areas of technology, the question of patent strategy will become increasingly important. It is our view that, in many cases, OICs cannot realistically avoid patents today. Instead, we believe that harnessing mechanisms, similar to those which OICs have used thus far to manage copyright risks, can help OICs employ defensive patenting to limit patent threats over time and eventually bring more stability to the patent system through private ordering. Therefore, in this Article, we

205. Richard J. Gilbert, Antitrust for Patent Pools: A Century of Policy Evolution, 2004 StAN. TeCh. L. REV. 3, 3 ๆ 2 (2004); see also U.S. DeP'T OF Justice \& FTC, ANTITRUST ENFORCEMENT AND INTELLECTUAL PROPERTY RIGHTS: PROMOTING INNOVATION AND COMPETITION 58 (2007), available at http://www.ftc.gov/reports/ innovation/P040101PromotingInnovationandCompetitionrpt0704.pdf ("Although both cross-licensing and patent-pooling agreements have the potential to generate significant efficiencies, they also may generate anticompetitive effects if the arrangements result in price fixing, coordinated output restrictions among competitors, or foreclosure of innovation.").

206. U.S. DEP'T OF JUSTICE \& FTC, supra note 205, at 63. 
present both a theoretical framework and an instrument for approaching OIC patent strategy questions in ways that are economically, culturally, and legally viable via the DPL. 
Appendix One: Model Defensive Patent License 207

NOTICE: ALL RIGHTS IN LICENSED PATENTS (as defined below) PROVIDED UNDER THIS DEFENSIVE PATENT LICENSE ("DPL") ARE SUBJECT TO ALL CONDITIONS AND LIMITATIONS BELOW. MAKING, USING, SELLING, OFFERING FOR SALE, IMPORTING, OR DISTRIBUTING PRODUCTS EMBODYING THE LICENSED PATENTS, OTHER THAN AS EXPLICITLY AUTHORIZED UNDER THIS LICENSE OR PATENT LAW, IS PROHIBITED.

\section{Definitions}

1.1 "Change of Control" means, with respect to a DPL User:

(a) the direct or indirect acquisition (except for transactions described in clause (b) of this paragraph below), whether in one or a series of transactions by any Entity or related Entities (the "Controlling Party") of (i) ownership, beneficial or otherwise, of issued and outstanding shares of capital stock of such DPL User, the result of which acquisition is that such Controlling Entity possesses $50 \%$ or more of the combined voting power of all then-issued and outstanding capital stock of such DPL User, or (ii) the power to elect, appoint, or cause the election or appointment of at least a majority of the members of the board of directors (or such other governing body that exercises a similar level of control) of such DPL User (in the event such DPL User or any successor Entity is not a corporation); or

(b) a merger, consolidation or other reorganization or recapitalization of such DPL User with an Entity or a direct or indirect subsidiary of such Entity (the "Surviving Party"), provided that the result of such merger, consolidation or other reorganization or recapitalization, whether in one or a series of related transactions, is that the holders of the outstanding voting stock of such DPL User immediately prior to such consummation do not possess, whether directly or indirectly, immediately after the consummation of such transaction, in excess of $50 \%$ of the combined voting power of all then-issued and outstanding stock of the Surviving Entity, or its direct or indirect parent.

207. Please note that this is truly a Model Defensive Patent License, created for purposes of this Article. It is not suitable for "off-the-shelf" use. If you are interested in using the DPL, please check http://defensivepatentlicense.com, where we will post updates about the license development, including any final license draft. You can also comment on the draft DPL and mark it up from this website. 
1.2 "Defensive Patent Claim" means an Infringement Claim asserted against a party in response to a prior Infringement Claim by said party against the asserter of the Defensive Patent Claim.

1.3 "Discontinuation Announcement" means a DPL User's announcement that:

(a) declares the DPL User's intent to discontinue its offer of its Patents for license under the DPL on the Discontinuation Date; and

(b) is submitted by an authorized representative of the Entity to the DPL Website six (6) months prior to a Discontinuation Date.

1.4 "DPL User" means an Entity that:

(a) has committed to offer a license under the DPL to each of its Patents and any Patents it may obtain in the future, or, if such Entity has no Patents, has committed to offer a license under the DPL to any Patents it may obtain in the future; and

(b) has declared such commitment by means of an Offering Announcement; and

(c) if the Entity has made a Discontinuation Announcement, the Discontinuation Date has not yet occurred.

1.5 "Discontinuation Date" means the date six (6) months after the date a Discontinuation Announcement is submitted to the DPL Website.

1.6 "DPL Website" means [a website to be established to publish DPL announcements]. ${ }^{208}$

1.7 "Entity" means an individual, corporation, trust, partnership, joint venture, limited liability company, association, unincorporated organization or other legal or governmental entity.

1.8 "Infringement Claim" means any claim of patent infringement made in a lawsuit, binding arbitration, or administrative action, or other filed legal proceeding (including but not limited to claims made before the International Trade Commission), including a counterclaim or cross-claim.

1.9 "License" and "DPL" mean the grant, conditions, and limitations herein.

208. The text within the brackets serves as a placeholder here. In live version of the DPL, this text would direct the users to the DPL's centralized website. See supra Part IV.A. 
1.10 "Licensed Patents" means any and all Patents (a) owned or controlled or acquired (including through acquisition of an Entity owning or controlling such Patent) by Licensor; or (b) under which Licensor has the right to grant licenses without the consent of or payment to a third party (other than an employee inventor).

1.11 "Licensed Products and Services" means products and services of Licensee that practice one or more claims of one or more Licensed Patents of a Licensor.

1.12 "Licensee" means any DPL User (other than Licensor) and any subsidiary, affiliate, or company in which such DPL User has a controlling (greater than 50\%) interest or which controls such DPL User, whether directly or indirectly, through one or more intermediaries.

1.13 "Licensor" means the Entity submitting an Offering Announcement and any subsidiary, affiliate, or company in which such Entity has a controlling (greater than 50\%) interest or which controls such Entity, whether directly or indirectly, through one or more intermediaries.

1.14 "Offering Announcement" means an Entity's announcement that:

(a) declares the Entity's commitment to offer its Patents for license under the DPL, or, if such Entity has no Patents, has committed to offer a license to any Patents it may obtain in the future under the DPL;

(b) contains the Entity's contact information; and

(c) is submitted to the DPL Website.

1.15 "Patent" means any right, now or later acquired, under any national or international patent law from a governmental body authorized to issue such rights, including rights embodied within patent applications, granted patents, including, but not limited to, continuations, continuations-in-part, divisionals, provisionals, results of any patent reexaminations, and reissues.

\section{License Grant}

2.1 Grant of License. Subject to the conditions and limitations of this License and upon affirmative assent to the commitments specified in Section 1.3 from an individual DPL User, each Licensor hereby grants and agrees to grant to such DPL User a worldwide, royalty-free, nocharge, non-exclusive, irrevocable (except as stated in Sections 2.2(e), 
2.2(f) and 2.2(g) below) license, perpetual for the term of the relevant Licensed Patents, to make, have made, operate, use, sell, offer for sale, import, or distribute Licensed Products and Services.

2.2 Restrictions and Exclusions. Notwithstanding the foregoing, this License is expressly subject to and limited by the following restrictions:

(a) This License does not include the right to sublicense any of the Licensed Patents.

(b) This License does not include any copyright, trademark, trade secret, other intellectual property, or other rights of Licensor other than the rights to Licensed Patents granted in Section 2.1. No such license or other right is granted herein by implication, estoppel or otherwise.

(c) This License does not include Patents with a priority date or Effective Filing Date later than Licensor's last Discontinuation Date that has not been followed by a subsequent Offering Announcement by Licensor.

(d) This License does not extend to any DPL User whose Offering Announcement occurs later than Licensor's last Discontinuation Date that has not been followed by a subsequent Offering Announcement by Licensor.

(e) Licensor reserves the right to revoke this License with regard to a named Licensee upon written notice if such named Licensee asserts any patent infringement claim in any form or forum, not including Defensive Patent Claims, against any DPL User, including but not limited to Licensor, and such named Licensee does not dismiss or otherwise withdraw its patent infringement claim within thirty (30) days after receiving such notice. In such event, Licensor shall retain its License to such named Licensee's Licensed Patents hereunder. In order to revoke, the revoking Licensor must include in its written notice to the named Licensee the fact that the Entity against whom the named Licensee has asserted the patent infringement claim is a DPL User. For the avoidance of doubt, a patent infringement claim made against an Entity that was not a DPL User at the time the claim was made does not trigger the revocation right under this Section 2.2(e), even if such Entity later becomes a DPL User.

(f) Licensor further reserves the right to revoke this License if Licensee discontinues being a DPL User, as of the date of such Licensee's Discontinuation Date.

(g) Licensor further reserves the right to revoke this License if Licensee transfers a Patent to an Entity other than a DPL User without 
conditioning the transfer on the transferee continuing to abide by the terms of this license for as long as Licensee is a DPL User.

\section{Assignment and Change of Control}

3.1 Assignment. No Licensor or Licensee may assign this Defensive Patent License or its rights hereunder, including but not limited to by operation of law, and any attempt to do so shall be void.

3.2 Change of Control. In the event that a DPL User undergoes a Change of Control, and the Controlling Party or Surviving Party, as applicable, is not itself a DPL User as of the effective date of such Change of Control, then the DPL User undergoing the Change of Control shall automatically cease to be a DPL User as of the effective date of such Change of Control and such effective date shall be deemed to be its Discontinuation Date, unless the Controlling Party or the Surviving Party, as applicable, elects to become a DPL User by issuing an Offering Announcement.

\section{Disclaimer of Warranties}

UNLESS OTHERWISE MUTUALLY AGREED TO BY THE
PARTIES IN WRITING, LICENSOR OFFERS THE PATENT
LICENSE GRANTED HEREIN "AS IS" AND MAKES NO
REPRESENTATIONS OR WARRANTIES OF ANY KIND
CONCERNING THE LICENSED PATENTS OR ANY PRODUCT
EMBODYING ANY LICENSED PATENT, EXPRESS OR
IMPLIED, STATUTORY OR OTHERWISE, INCLUDING,
WITHOUT LIMITATION, WARRANTIES OF TITLE,
MERCHANTIBILITY, FITNESS FOR A PARTICULAR PURPOSE,
NONINFRINGEMENT, OR THE PRESENCE OR ABSENCE OF
ERRORS, REGARDLESS OF THEIR DISCOVERABILITY. SOME
JURISDICTIONS DO NOT ALLOW THE EXCLUSION OF
IMPLIED WARRANTIES, IN WHICH CASE SUCH EXCLUSION
MAY NOT APPLY TO LICENSEE. Without limiting the generality
of the foregoing, each Licensor makes no representations and
disclaims any and all warranties as to title or the validity of its
Licensed Patents or that the exercise of the License granted by
Licensor hereunder will not infringe the patent, copyright, trademark,
trade secret, or other intellectual property rights of any other party.


5. Disclaimer of Liability

LICENSOR SHALL NOT BE LIABLE FOR ANY DAMAGES ARISING FROM OR RELATED TO THIS LICENSE, INCLUDING INDIRECT, INCIDENTAL, CONSEQUENTIAL, PUNITIVE OR SPECIAL DAMAGES, WHETHER ON WARRANTY, CONTRACT, NEGLIGENCE, OR OTHERWISE, EVEN IF LICENSOR HAS BEEN ADVISED OF THE POSSIBILITY OF SUCH DAMAGES PRIOR TO SUCH AN OCCURRENCE.

\section{Miscellaneous}

Nothing contained in this Agreement or the performance thereof is intended or shall be construed to create any relationship of agency, partnership or joint venture between or among the parties. Nothing in this Agreement shall be construed as an agreement by a Licensor to bring actions or suits against non-DPL Users for infringement of its Licensed Patents, or conferring any right to a Licensee to bring actions or suits against third parties for infringement of the Licensed Patents. The provisions of this Agreement shall continue to apply in accordance with their terms even after the withdrawal of an Entity from the DPL through issuance of a Discontinuation Notice.

Each DPL User acknowledges and agrees that a significant benefit and consideration for entering into this Agreement is to avoid the risks and uncertainty of litigation with respect to the Licensed Patents of other DPL Users, a benefit which derives in significant part from the license rights that each DPL User receives collectively from all other DPL Users, and the DPL therefore does not reflect a royalty that any DPL User might otherwise have negotiated at arms' length with respect to any one or more particular Licensed Patents apart from this Agreement and its collective license rights, nor what would constitute a reasonable royalty or a measure of damages with respect to the enforcement of any particular Licensed Patent in any dispute or transaction outside the scope of this Agreement. Each DPL user further agrees that it obtains a unique benefit from the portfolio-wide nature of the cross-licenses granted herein, and that infringement of any particular patent(s) subject to this Agreement therefore may not be adequately compensated by money damages, notwithstanding the existence of the licenses granted hereunder to such patent(s). 
Each DPL User shall be a third party beneficiary of this Agreement with the right to enforce the terms and conditions of this Agreement directly against Licensor. 